\title{
Modeling a Set of Heavy Oil Aqueous Pyrolysis Experiments
}

\author{
Charles B. Thorsness
}

John G. Reynolds

November 1996

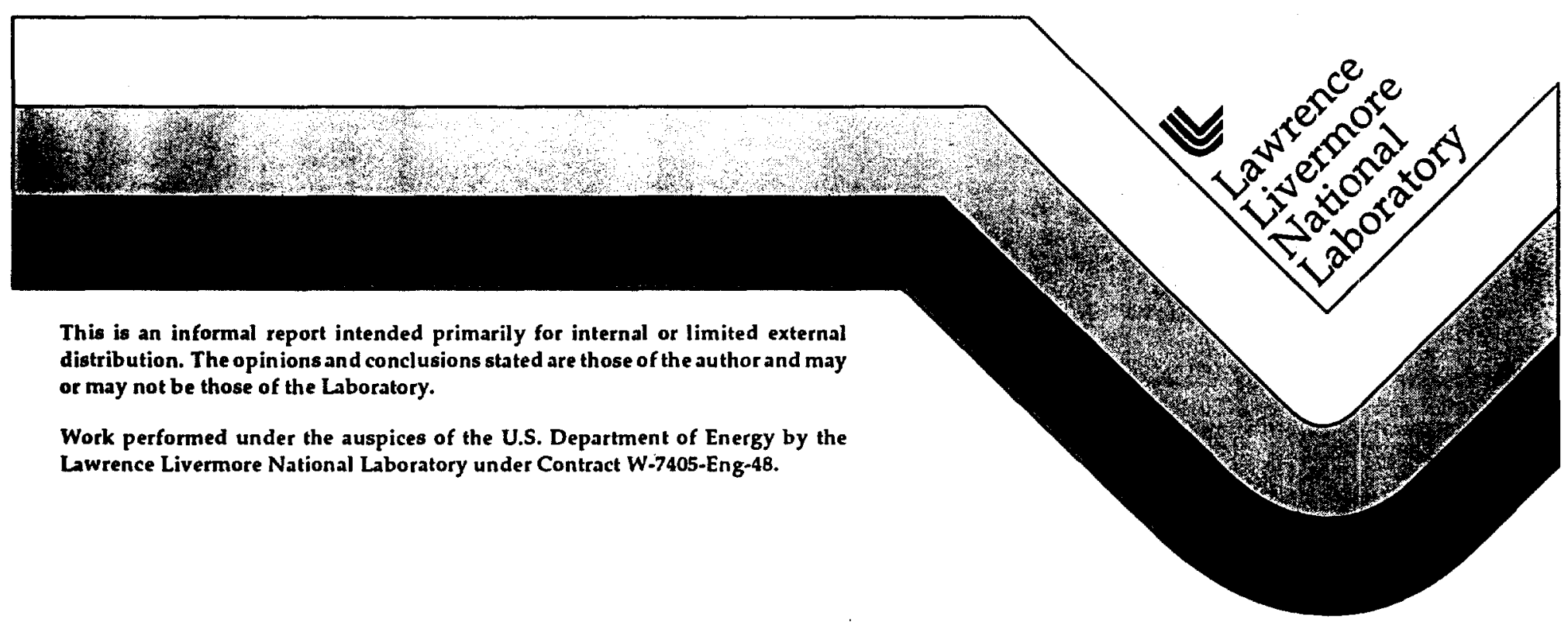




\section{DISCLAIMER}

This document was prepared as an account of work sponsored by an agency of the United States Government. Neither the United States Government nor the University of Calformia nor any of their employees, makes any warranty, express or implied, or asumes any legal liability or respensibility for the accuracy, completeness, or usefulness of any information, apparatus, product, or process disclosed, or represents that its use would not infringe privately owned rights. Reference herein to any specific commercial products, process, or service by trade anme, trademark, manufacturer, or otherwise, does not necesarily constitute or inply its endorsement, recommendation, or favoring by the United States Government or the University of Callfornia. The views and opinions of authors expressed herein do not necessarily state or refiect those of the United States Government or the University of California, and shall not be used for advertising or product endorsement purposes.

This report has been reproduced directly from the best avallable copy.

Available to DOE and DOE contractors from the Orice of Scientific and Technical Information

P.O. Box 62, Oak Ridge, TN 37831

Prices available from (615) 576-8401, FTS 626-8401

Avalable to the public from the

National Technical Information Service

US. Department of Corntmerce

5285 Port Royal Rd,

Springfield, VA 22161 


\title{
MODELING A SET OF HEAVY OIL AQUEOUS PYROLYSIS EXPERIMENTS
}

\author{
Charles B. Thorsness \\ John G. Reynolds
}

\begin{abstract}
Aqueous pyrolysis experiments, aimed at mild upgrading of heavy oil, were analyzed using various computer models. The primary focus of the analysis was the pressure history of the closed autoclave reactors obtained during the heating of the autoclave to desired reaction temperatures. The models used included a means of estimating nonideal behavior of primary components with regard to vapor liquid equilibrium. The modeling indicated that to match measured autoclave pressures, which often were well below the vapor pressure of water at a given temperature, it was necessary to incorporate water solubility in the oil phase and an activity model for the water in the oil phase which reduced its fugacity below that of pure water. Analysis also indicated that the mild to moderate upgrading of the oil which occurred in experiments that reached $400^{\circ} \mathrm{C}$ or more using a $\mathrm{Fe}$ (III) 2-ethylhexanoate could be reasonably well characterized by a simple first order rate constant of $1.7 \times 10^{8}$ $\exp (-20000 / \mathrm{T}) \mathrm{s}^{-1}$. Both gas production and API gravity increase were characterized by this rate constant. Models were able to match the complete pressure history of the autoclave experiments fairly well with relatively simple equilibria models. However, a consistent lower than measured buildup in pressure at peak temperatures was noted in the model calculations. This phenomena was tentatively attributed to an increase in the amount of water entering the vapor phase caused by a change in its activity in the oil phase.
\end{abstract}




\section{INTRODUCTION}

Heavy crude oil with an API gravity below 20 generally has a considerably lower market value then benchmark crudes because of undesirable physical and chemical properties (e.g., high viscosity and high heteroatom content). One strategy to increase the value of these crude oils and allow easier transport by existing pipelines is in-field upgrading. Aqueous pyrolysis is one candidate for in-field upgrading of heavy oils. It involves heating an oil-water mixture under pressure, possibly with a catalyst present, to partially crack and coke the heavy constituents and thus improve the oil quality. This process is attractive since the heavy oils are often associated with some thermally assisted recovery process, such as steam flooding, and as a result are often produced at somewhat elevated temperatures and with considerable water. The produced fluids, therefore, already require some form of dewatering step to allow them to be marketed, and the aqueous pyrolysis process can be viewed as an extension of the dewatering process.

As a first step in exploring the potential of aqueous pyrolysis as an in-field upgrading step, a series of autoclave experiments have been performed to obtain data on the conditions needed to allow significant modification of a typical heavy crude. These experiments ${ }^{1}$ yielded information on API gravity change, coke formation, and gas yield over a temperature range of $350-425^{\circ} \mathrm{C}$ and pressures up to $30 \mathrm{MPa}$.

Probably the most important parameter in determining the economic viability of an aqueous pyrolysis process is the pressure at which the process must operate. Since in the aqueous pyrolysis process it is necessary to maintain water in a liquid phase, these pressures are potentially quite high-the vapor pressure of water at $350^{\circ} \mathrm{C}$ is $165 \mathrm{MPa}(2390 \mathrm{psia})$. Results from autoclave experiments are difficult to use directly as a guide for pressure requirements for an actual process. This is because the autoclave is a closed system with a fixed volume. In an actual process, venting of vapor is often desirable to control the process pressure and minimize required reactor volumes. This means that the phase composition of autoclave liquid and process liquids are potentially different.

To be able to estimate the pressure behavior of a proposed aqueous pyrolysis process it is important that some account of the interchange between liquid and vapor states occurring within the autoclave be understood. This is important not only from the standpoint of extrapolating the autoclave data to other more process related systems, but also to allow the maximum amount of data to be obtained from the experiments. Since the autoclave experiments involve heating a mixture from room temperature to reaction conditions and then cooling the system back to room temperature the pressure history of the autoclave can be fairly complicated. This is a result of the production of gas and vapors from the decomposition reactions and the exchange of components between the vapor and liquid phases. 
The aim of this report is to analyze available data, primarily the pressure history data, from a series of autoclave experiments. The analysis involves simple material balance considerations and application of mathematical models. Particular attention is paid to the water component since its behavior is a major contributor to overall pressure response of the system.

\section{SUMMARY OF EXPERIMENTAL DATA}

The details of the experimental series is given elsewhere 1 . This section is a brief description and summary of the run series. The data of interest was generated using a typical California heavy crude with an API gravity of $13.5^{\circ}$. Selected analytical data for the crude is given in Appendix I.

The autoclave experiments were done in vessels with an approximate volume of one liter. The reactors were typically half filled with oil-water mixtures. The gas space was filled with nitrogen. The experimental setup allowed the reactor and its contents to be heated and gently rocked. During the duration of an experiment, furnace and internal reactor temperatures were recorded along with the reactor pressure. A typical temperature and pressure history for the active period of an experiment is shown in Fig. 1. The active period of the experiment, heatup and isothermal intervals, typically lasted about eight hours while the cool-down period was about 24 hours. Most experiments included a nearly isothermal interval of about 30 minutes at the reaction temperature of choice. For the case of Experiment 126 shown in Fig. 1, the plateau temperature was about $425^{\circ} \mathrm{C}$. Immediately following the isothermal interval, the furnace was turned off and temperature began to drop. The rate of initial decrease, based on an average of a number experiments is about $1^{\circ} \mathrm{C}$ per minute. 


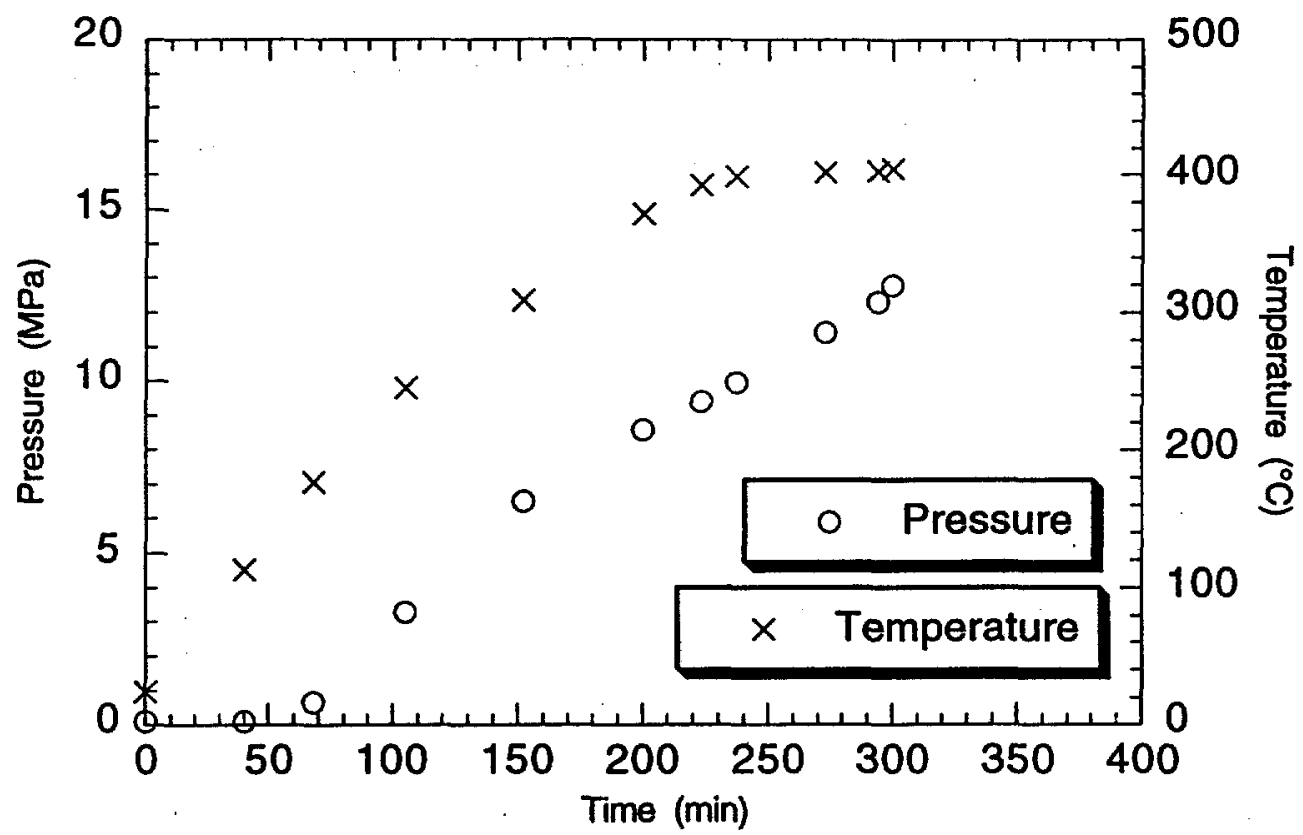

Figure 1. Pressure and temperature history for Experiment 126, final pressure and temperature were $22^{\circ} \mathrm{C}$ and $0.96 \mathrm{MPa}$ at $1249 \mathrm{~min}(20.8 \mathrm{hrs})$.

At the end of each experiment, after the reactor and its contents had been returned to near room temperature, a small gas sample was removed for gas chromatographic analysis. In addition, coke and oil yield and final API oil gravity were determined.

In may of the experiments, a catalyst was used to improve cracking and a surfactant was employed to enhance the mixing of the oil and water phases. In several experiments only water was added, and in two experiments the system consisted of only water and nitrogen. These water-nitrogen experiments were done to help verify model computations.

Table 1 lists information on oil-water mixture runs. The catalysts are designated by their catalytic action. The actual catalyst were: Fe-III 2-ethylhexanoate, $\mathrm{CuCl}_{2}$, $\mathrm{NaMoO}_{3}, \mathrm{Zn}\left(\mathrm{NO}_{3}\right)_{2}, \mathrm{Ni}\left(\mathrm{NO}_{3}\right)_{2}$ and $\mathrm{Co}-\mathrm{II}$ 2-ethylhexanoate. The measurements of coke yields were difficult and in may cases required some estimation to be done. Experiment 96 was performed with crude oil which had been totally dewatered using a toluene distillation. It was estimated that approximately $4.5 \mathrm{wt} \%$ toluene remained in the final oil after dewatering. In estimating the water content of the mixtures, a value of $1.25 \mathrm{wt} \%$ water in the oil obtained from the dewatering test was used in addition to the water actually added to the mixture. 
Table 1. Summary information on experimental autoclave runs.

\begin{tabular}{|c|c|c|c|c|c|c|c|c|c|c|c|}
\hline Exp. & $\begin{array}{c}\text { Total Load } \\
\text { (kg) }\end{array}$ & $\begin{array}{c}\text { Reactor Vol. } \\
(\infty)\end{array}$ & $\begin{array}{l}\text { Water } \\
(w 1 \%)\end{array}$ & $\begin{array}{l}\text { Catalyst } \\
(w 1 \%)\end{array}$ & $\begin{array}{l}\text { Catalyst } \\
\text { Type }\end{array}$ & Surfactant & $\begin{array}{c}\text { Maximum } \\
\left({ }^{\circ}\right)\end{array}$ & $\begin{array}{l}\text { laximum P } \\
\text { (MPa) }\end{array}$ & $\begin{array}{c}\text { Est. Coke } \\
\text { (gm) }\end{array}$ & $\begin{array}{c}\text { Product API } \\
\text { Gravity }\end{array}$ & $\begin{array}{l}\text { Final } \mathbf{P} \\
(\mathrm{MPa})\end{array}$ \\
\hline 86 & 0.498 & 1050 & $3.5 \%$ & $0 \%$ & & no & 350 & 5.9 & $\overline{0}$ & 13.7 & 0.10 \\
\hline 88 & 0.497 & 1050 & $6.2 \%$ & $0 \%$ & & no & 354 & 10.4 & 0 & 13.6 & 0.10 \\
\hline 90 & 0.505 & 1050 & $9.2 \%$ & $0 \%$ & & no & 350 & 11.7 & 0 & 13.6 & 0.10 \\
\hline 94 & 0.501 & 1050 & $1.2 \%$ & $0 \%$ & & no & 354 & 2.9 & 0 & 13.6 & 0.10 \\
\hline 96 & 0.500 & 1050 & $0.0 \%$ & $0 \%$ & & no & 350 & 0.9 & 0 & 13.9 & \\
\hline 100 & 0.494 & 1050 & $6.1 \%$ & $0 \%$ & & yes & 358 & $\overline{8.3}$ & $\overline{0}$ & & 0.10 \\
\hline 106 & 0.488 & 1050 & $7.3 \%$ & $1 \%$ & Mo & yes & 405 & 12.5 & 5.2 & 16.9 & 0.93 \\
\hline 108 & 0.384 & 784 & $6.0 \%$ & $1 \%$ & Fe-III & yes & 412 & 14.4 & 0 & 17.5 & 1.27 \\
\hline 110 & 0.495 & 1050 & $6.1 \%$ & $0 \%$ & & yes & 354 & 8.2 & 0 & 14.0 & 0.10 \\
\hline 112 & 0.492 & 1050 & $6.0 \%$ & $0.25 \%$ & Mo & yes & 403 & 12.2 & 9.6 & 17.4 & 0.93 \\
\hline 114 & 0.375 & 784 & $6.0 \%$ & $1 \%$ & Co-II & yes & 403 & 14.0 & 10.7 & 19.3 & 1.34 \\
\hline 116 & 0.493 & 1050 & $6.0 \%$ & $0.25 \%$ & Mo & yes & 428 & 20.0 & 33.8 & 18.3 & 2.58 \\
\hline 120 & 0.489 & 1050 & $6.0 \%$ & $1 \%$ & Fe-III & yes & 402 & 12.0 & 1 & 16.8 & 0.86 \\
\hline 122 & 0.493 & 1050 & $6.0 \%$ & $0.25 \%$ & Fe-III & yes & 405 & 12.8 & 1 & 17.9 & 0.96 \\
\hline 124 & 0.377 & 784 & $6.0 \%$ & $1 \%$ & $\mathrm{Cu}$ & yes & 407 & 15.0 & 3.2 & 19.3 & 1.75 \\
\hline 126 & 0.491 & 1050 & $6.0 \%$ & $0.25 \%$ & Fe-III & yes & 429 & 19.4 & 25 & 22.0 & 2.38 \\
\hline 2 & 0.378 & 784 & $6.0 \%$ & $0.25 \%$ & Fe-III & yes & 359 & 8.6 & 0 & & 0.58 \\
\hline 4 & 0.494 & 1050 & $6.0 \%$ & $0 \%$ & & yes & 401 & 11.8 & 0.5 & 16.9 & 0.79 \\
\hline 6 & 0.493 & 1050 & $30.0 \%$ & $0.25 \%$ & Fe-III & no & 402 & 28.5 & 0 & 17.0 & 0.79 \\
\hline 8 & 0.376 & 784 & $6.0 \%$ & $1 \%$ & $\mathrm{Zn}$ & yes & 361 & 9.3 & 0 & 13.7 & 0.10 \\
\hline 10 & 0.491 & 1050 & $30.0 \%$ & $1 \%$ & Co-II & no & 405 & 29.4 & 9.2 & 16.8 & 1.13 \\
\hline 12 & 0.376 & 784 & $6.0 \%$ & $1 \%$ & Fe-III & yes & 356 & 8.0 & 0 & 13.7 & 0.10 \\
\hline 14 & 0.489 & 1050 & $1.2 \%$ & $1 \%$ & Co-II & yes & 403 & 7.2 & 31 & 19.9 & 1.82 \\
\hline 16 & 0.375 & 784 & $6.0 \%$ & $1 \%$ & Co-II & yes & 358 & 8.2 & & 14.2 & 0.10 \\
\hline 18 & 0.491 & 1050 & $6.0 \%$ & $1 \%$ & Co-II & no & 403 & 12.3 & 6.2 & 17.7 & 1.07 \\
\hline 20 & 0.376 & 784 & $6.0 \%$ & $1 \%$ & $\mathrm{Zn}$ & yes & 385 & 10.6 & 0 & 15.6 & 0.31 \\
\hline 21 & 0.374 & 784 & $5.8 \%$ & $1 \%$ & $\mathrm{CO}-\mathrm{II}$ & yes & 360 & 7.7 & 0 & 14.2 & \\
\hline 22 & 0.377 & 1050 & $5.8 \%$ & $1 \%$ & $\mathrm{Ni}$ & yes & 356 & 9.1 & & 13.7 & \\
\hline 29 & 0.526 & 1050 & $6.0 \%$ & $0.25 \%$ & $\mathrm{Fe}$-III & yes & 413 & 23.8 & 31.5 & & \\
\hline
\end{tabular}

The extent of reaction can be gauged by the change in API gravity from the feed gravity of 13.5, by the amount of coke produced and by the amount of gas produced as measured by the final pressure. Table 1 indicates that experiments in which the peak temperature was below about $400^{\circ} \mathrm{C}$ show little evidence of reaction. Two of the three experiments, 116 and 126, showing the most reaction reached temperatures above $425^{\circ} \mathrm{C}$. Results from the third experiment of this group, 29, indicate nearly as much reaction as runs 116 and 126 , but it only reached $413^{\circ} \mathrm{C}$. However, this run was held at the plateau temperature for an extended period of time, 150 minutes versus the normal 30 minutes.

\section{PRESSURE DATA ANALYSIS}

The first series of experiments $(86,88,90$, and 94$)$ were performed using no catalyst and no surfactant. The maximum temperature was limited to about $350^{\circ} \mathrm{C}$. No significant pyrolysis appeared to occur in any of these runs. However, the maximum pressure reached in each run varied over a considerable range. This was a direct result of the varying amount of water included in the mixture. The pressure responses as a function temperature are plotted in Fig. 2. Included in the figure is the vapor pressure of water. The measured pressure for each experiment 
tracks the vapor pressure of water up to a given temperature. The point of departure increases in temperature with the amount of water in the feed mixture.

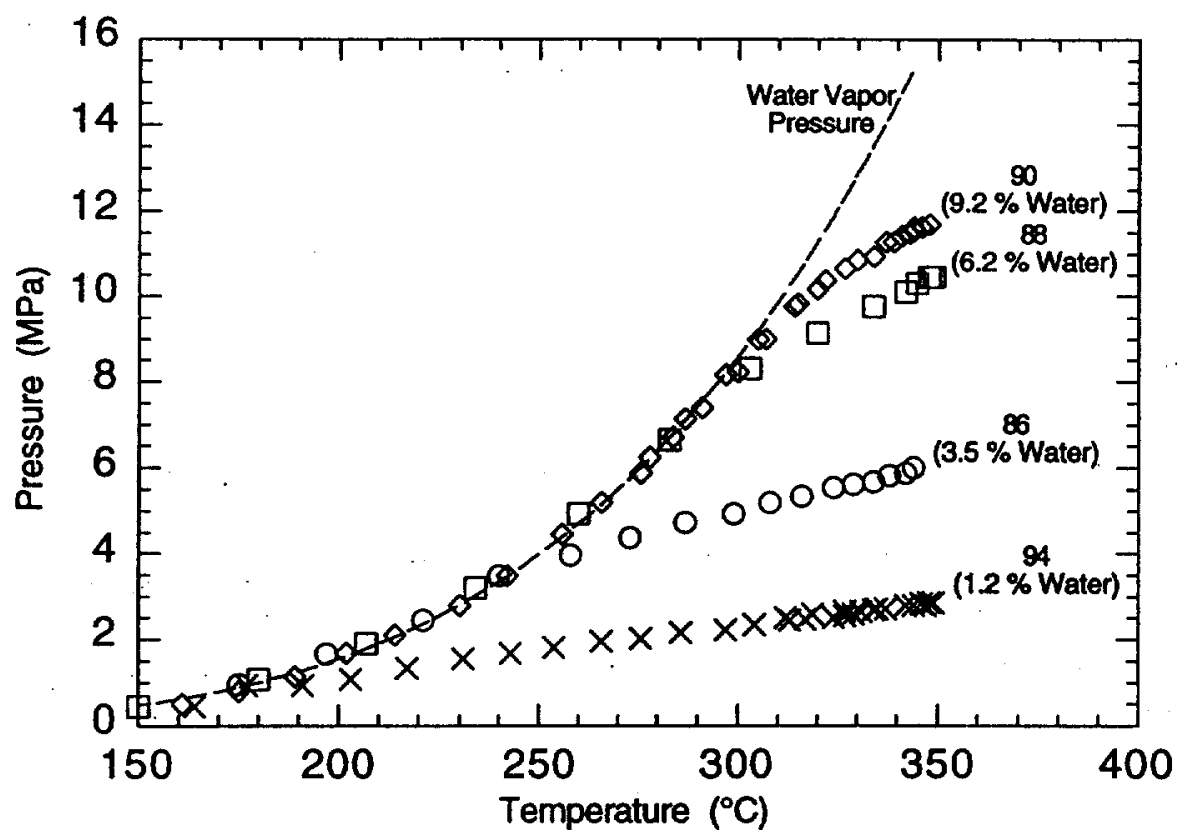

Figure 2. Pressures for low temperature runs with no surfactant or catalyst.

One explanation for the behavior shown in Fig. 2 is that all the water eventually evaporates. Consequently, the measured autoclave pressure deviates from the water vapor pressure curve because the liquid water phase vanishes. The results shown in Fig. 2 qualitatively are consistent with this hypothesis since the deviation from the water vapor pressure curve occurs and higher pressures in experiments in which more water is present. In Table 2, estimates of the amount of water in the vapor phase have been made for each these runs based on a simple estimate of the void volume and vapor density. The vapor density (assumed to be steam) was obtained from steam tables. The temperatures shown in the table were obtained by estimating a value at which the first significant deviation of the measured pressure from the water vapor pressure was noted for each run. These estimates indicate that deviation from the water vapor pressure curve occurs before all the water is in the vapor phase. This suggests that the liquid water fugacity is reduced by some mechanism. The simplest explanation is that the water is partially soluble in the oil phase and its activity coefficient is such that its fugacity is less than that of a pure water phase. 
Table 2. Estimate of the amount of water in the vapor phase.

\begin{tabular}{|cccccc|}
\hline Exp. & $\begin{array}{c}\text { Water } \\
(\text { wt. \%) }\end{array}$ & $\begin{array}{c}\mathrm{T} \\
\left({ }^{\circ} \mathrm{C}\right)\end{array}$ & $\begin{array}{c}\text { Sat. Water } \\
\text { Density } \\
\left(\mathrm{kg} / \mathrm{m}^{\star}{ }^{\star} 3\right)\end{array}$ & $\begin{array}{c}\text { Vapor } \\
\text { Volume } \\
(\mathrm{cc})\end{array}$ & $\begin{array}{c}\text { Water Vapor, } \\
\% \text { of Total } \\
\text { Water }\end{array}$ \\
\hline 94 & 1.2 & 190 & 6.394 & 491 & $50 \%$ \\
86 & 3.5 & 260 & 23.72 & 477 & $65 \%$ \\
88 & 6.2 & 300 & 46.21 & 478 & $72 \%$ \\
90 & 9.2 & 310 & 54.58 & 482 & $57 \%$ \\
\hline
\end{tabular}

Water is known to be somewhat soluble in oils. The results in Table 2 suggest that water in oil solubilities of 0.5 to $5 \mathrm{wt} \%$ would be required. Hooper, Michel, and Prausnit $z^{2}$ have summarized data for water-organic mixtures including components related to crude oils. They show water solubility in organics increases with temperature, as suggested by Table 2, and solubilities of as high as $80 \mathrm{~mol} \%$ are reported. The solubility indicated by Table 2 translated into a mole basis are approximately $8-90 \mathrm{~mol} \%$. Therefore, it is concluded that water solubility in the oil phase is an important consideration in understanding the pressure behavior of the autoclave experiments.

To further explore the nature of the pressure responses, a computer model, the Autoclave Simulator Model (ACS), has been employed. This model, describe more fully in reference 3, was developed to compute the pressure response of a closed autoclave system undergoing a heating and cooling sequence. The model solves mass balance equations and equilibrium constraints for a system which may include decomposition reactions that generate new species. The model can use an ideal gas assumption to compute gas phase component fugacities or a several simple equation-of-state models including the Redlich-Kwong equation. Provisions have been made in the liquid phase to handle the partial solubility of water in an oil phase. Changes in liquid densities are assumed available from simple temperature density tables. Fugacities of liquid components can be computed using an ideal mixing assumption or a simple Hilderbrand-Scatchard model ${ }^{4}$.

The ACS model was used to look more carefully at the pressure behavior of the first series of experiments. Since the pressures and temperatures reached in these experiments are high relative to the critical point of water $\left(374.2^{\circ} \mathrm{C}\right.$ and $\left.22.05 \mathrm{MPa}\right)$ nonideal behavior in the gas phase was included by using the Redlich-Kwong equation of state option. The pure component vapor pressure of the constituents was estimated using simple corresponding state model based on the component's normal boiling point 5 . However, the water vapor pressure was obtained from steam tables. Results for simple water-nitrogen only autoclave runs indicate that computed results obtained utilizing the simple Redlich-Kwong equation to compute gas phase fugacities did a fairly good job in matching the measured pressure response. See Appendix II for comparisons between computed and measured pressures. 
Pseudocomponents are used to model the complicated crude oil composition. These pseudocomponents and their properties were obtained by using facilities available in a commercial process simulation product, ASPEN PLUS. Using measured boiling point curves, the following set of pseudocomponents were developed to represent the crude oil used in the experiments. They are listed in Table 3 along with their important characterizing properties.

Table 3. Pseudocomponents used to simulate crude oil

\begin{tabular}{|ccccccccc|}
\hline Name & $\begin{array}{c}\text { MW } \\
\text { (gm/mole) }\end{array}$ & wt \% & $\begin{array}{c}\text { Specific } \\
\text { gravity }\end{array}$ & $\begin{array}{c}\text { Boiling } \\
\text { Point } \\
\left({ }^{\circ} \mathrm{C}\right)\end{array}$ & $\begin{array}{c}\text { Critical } \\
\text { Temp } \\
\left({ }^{\circ} \mathrm{C}\right)\end{array}$ & $\begin{array}{c}\text { Critical } \\
\text { Pres } \\
\text { (MPa) }\end{array}$ & $\begin{array}{c}\text { Acentric } \\
\text { Factor }\end{array}$ & $\begin{array}{c}\text { API } \\
\text { Gravity }\end{array}$ \\
\hline HNAPH & 142 & 5.00 & 0.844 & 186 & 387 & 2.61 & 0.37 & 36.1 \\
KERO & 178 & 6.00 & 0.877 & 241 & 443 & 2.19 & 0.46 & 29.9 \\
AGO & 228 & 12.00 & 0.911 & 304 & 504 & 1.83 & 0.57 & 23.7 \\
LVGO & 307 & 16.10 & 0.954 & 388 & 583 & 1.48 & 0.73 & 16.9 \\
HVGO & 411 & 26.80 & 1 & 483 & 668 & 1.21 & 1 & 10.4 \\
VR & 540 & 34.10 & 1.04 & 588 & 759 & 0.99 & 1.29 & 4.4 \\
\hline
\end{tabular}

The first set of computations was done to confirm the importance of the water in oil solubility effect. In the calculations, water was assumed insoluble in oil at all temperatures. Results of the calculations are shown in Fig. 3. The simple model does a fairly good job in matching the no water Experiment 96 . However, for those runs containing water, the model predicts, in general, considerably higher pressures than those measured. 


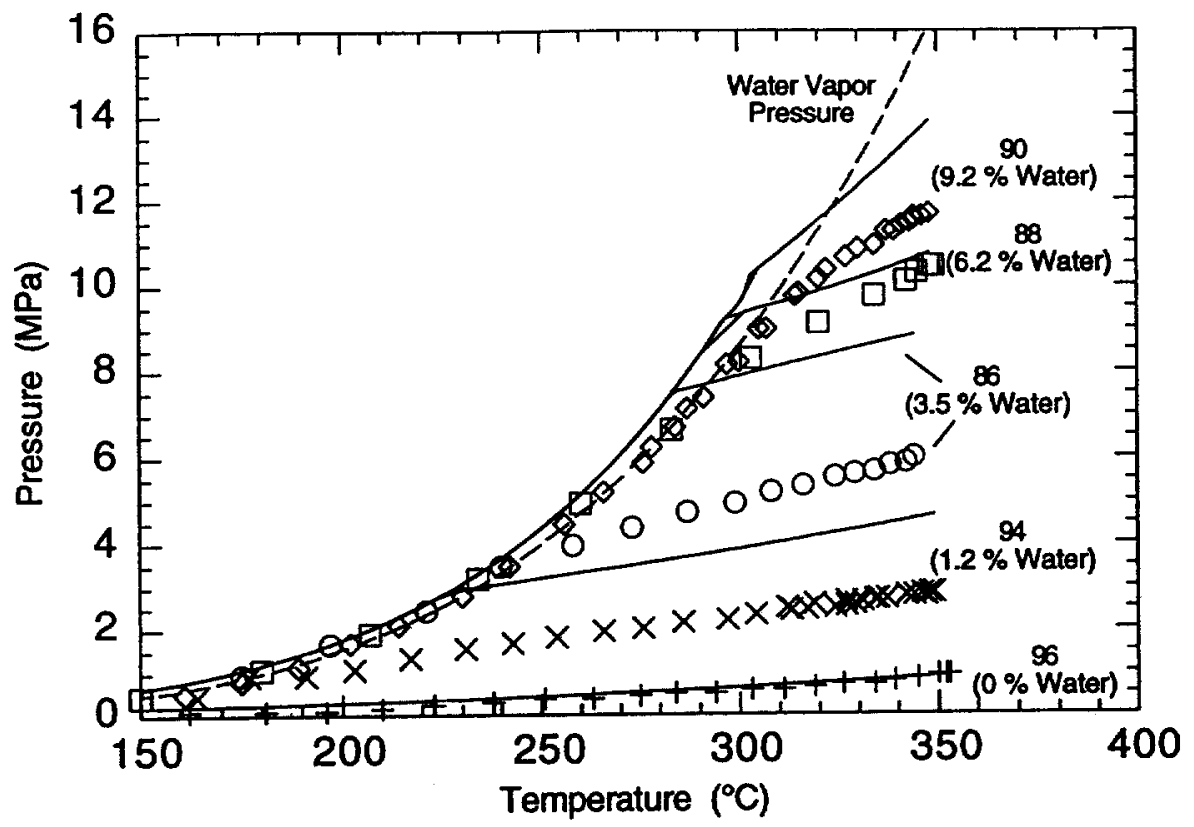

Figure 3. Experimental and computed pressure responses for runs with no surfactant or catalyst assuming no solubility of water in the oil phase.

The model calculations were repeated assuming some solubility of water in the oil phase. The amount of solubility was adjusted to give the best fit of the pressure data. The solubility curve developed was constrained to maintain a smooth solubility behavior with temperature. The results of the calculations and the solubility curve used are shown in Figs. 4 and 5. Although not perfect, the computed results agree much better with the measured pressure data than the pressure computed assuming no water solubility. 


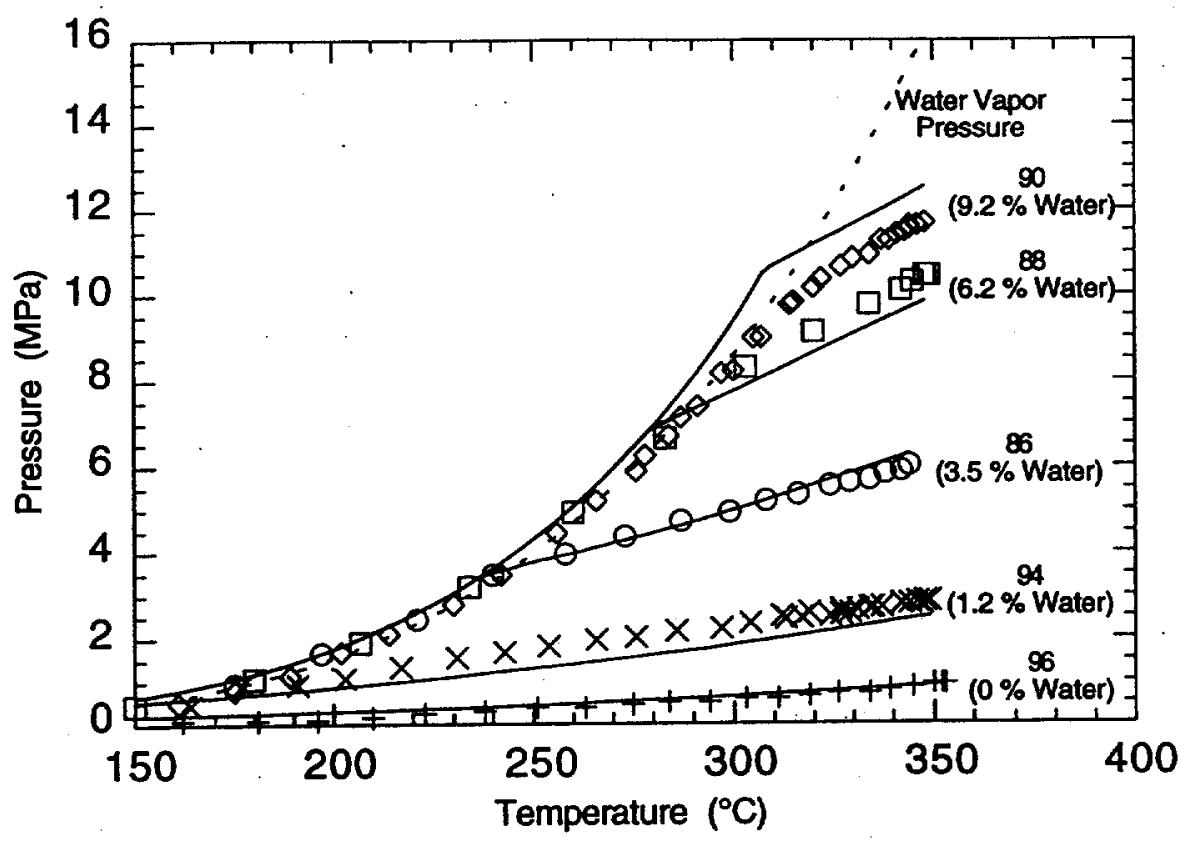

Figure 4. Experimental and computed pressure responses for runs with no surfactant or catalyst assuming some solubility of water in the oil phase.

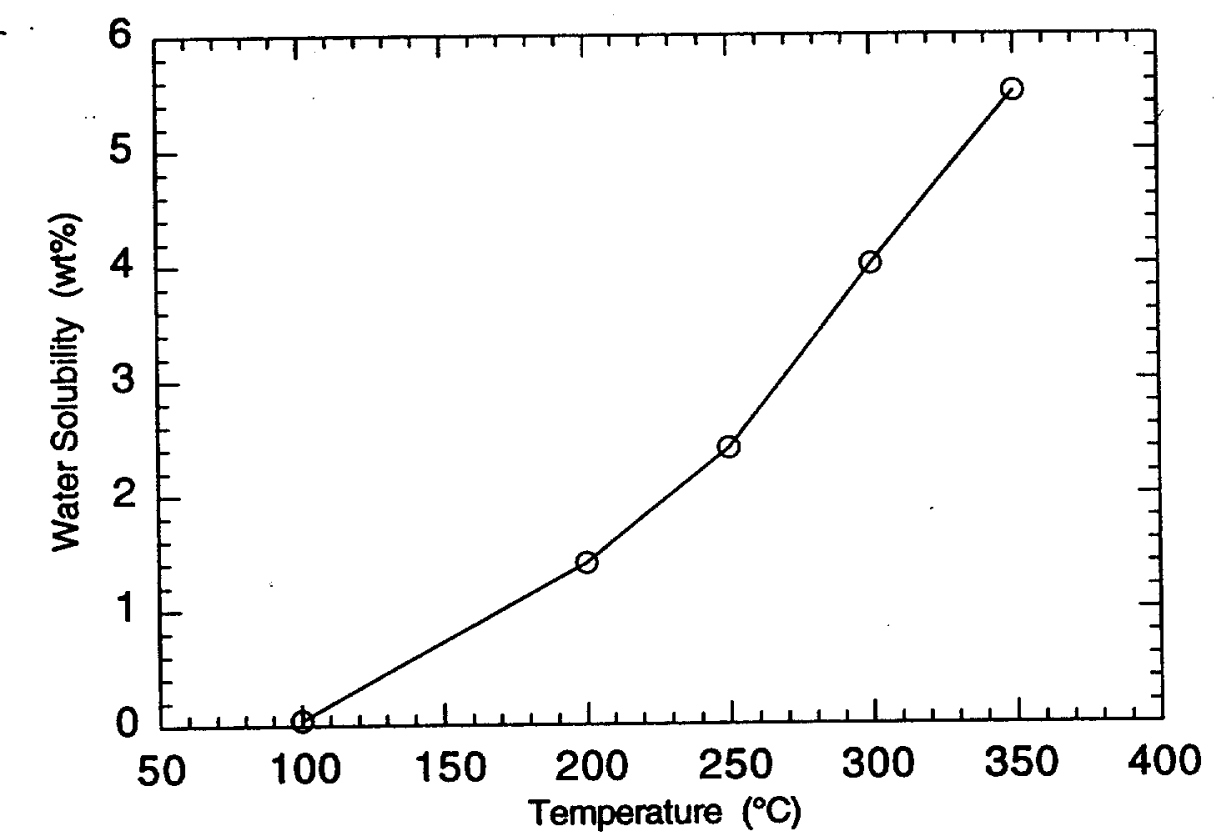

Figure 5. Water solubility in oil used in computing results for experiments in which no surfactant is present.

In the model, the activity coefficient of water dissolved in the oil was estimated using a simple relation suggested by relations used in the ASPEN PLUS $^{6}$ simulator package. The simple solution theory relation available in 
ACS is inadequate since it does not correctly predict the activity coefficient at the point of full water saturation of the organic phase. This activity coefficient must be given by

$$
\gamma_{1}=\frac{1}{x_{1}},
$$

where $x_{1}$ is mole fraction of water in the oil phase. For conditions below saturation the following simple relation is incorporated into the model

$$
\gamma_{1}=\frac{1}{\left(x_{1}^{s}\right)^{\alpha_{s}} x_{1}^{1-\alpha_{s}}}
$$

where $x_{1}^{s}$ is the water mole fraction at saturation at the temperature of interest and $\alpha_{s}$ is a parameter. An $\alpha_{s}$ equal to one was used in the calculations which leads to a constant activity coefficient.

After the initial series of runs, most of the experiments were done using a surfactant to increase the contact between oil and water phases. It was found that surfactant influenced the pressure response by reducing it somewhat with respect to the runs with no surfactant and limited water content. This is illustrated in Fig. 6 where the pressure responses from a number of surfactant containing runs are plotted. All these runs had a $6 \mathrm{wt} \%$ water content in the initial oil-water mixture. Three pressure curves computed using the ACS model are also shown in the figure. The computed curves were generated using different assumptions about the solubility of water in the oil phase; 1) no water solubility; 2) solubility used to match the no surfactant data; and 3) a solubility curve shifted to match the data for systems with surfactant present. Note that the data for all runs is fairly consistent below about $400^{\circ} \mathrm{C}$ and is matched fairly well by the pressure computed using the shifted solubility curve. The rapid increase in the pressure above $400^{\circ} \mathrm{C}$, seen in Fig. 6 , is a result of gas production by the pyrolysis reactions in this region. 


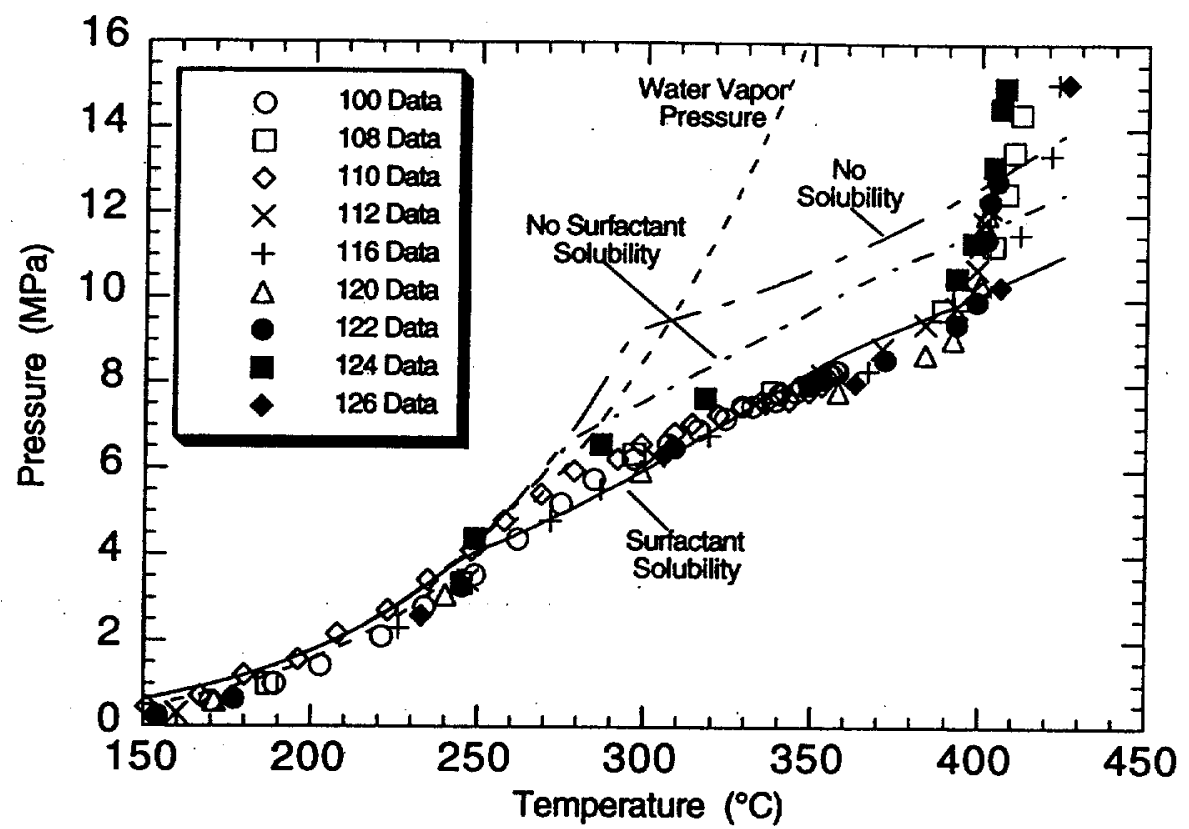

Figure 6. Experimental and computed pressure responses for runs have a $6 \mathrm{wt} \%$ water content and surfactant present. The computed results are shown for three different assumptions concerning water solubility in the oil phase.

The shifted solubility curve was obtained from the no surfactant curve by multiplying by a simple factor and extending the relation above $350^{\circ} \mathrm{C}$. The curves are compared in Fig. 7.

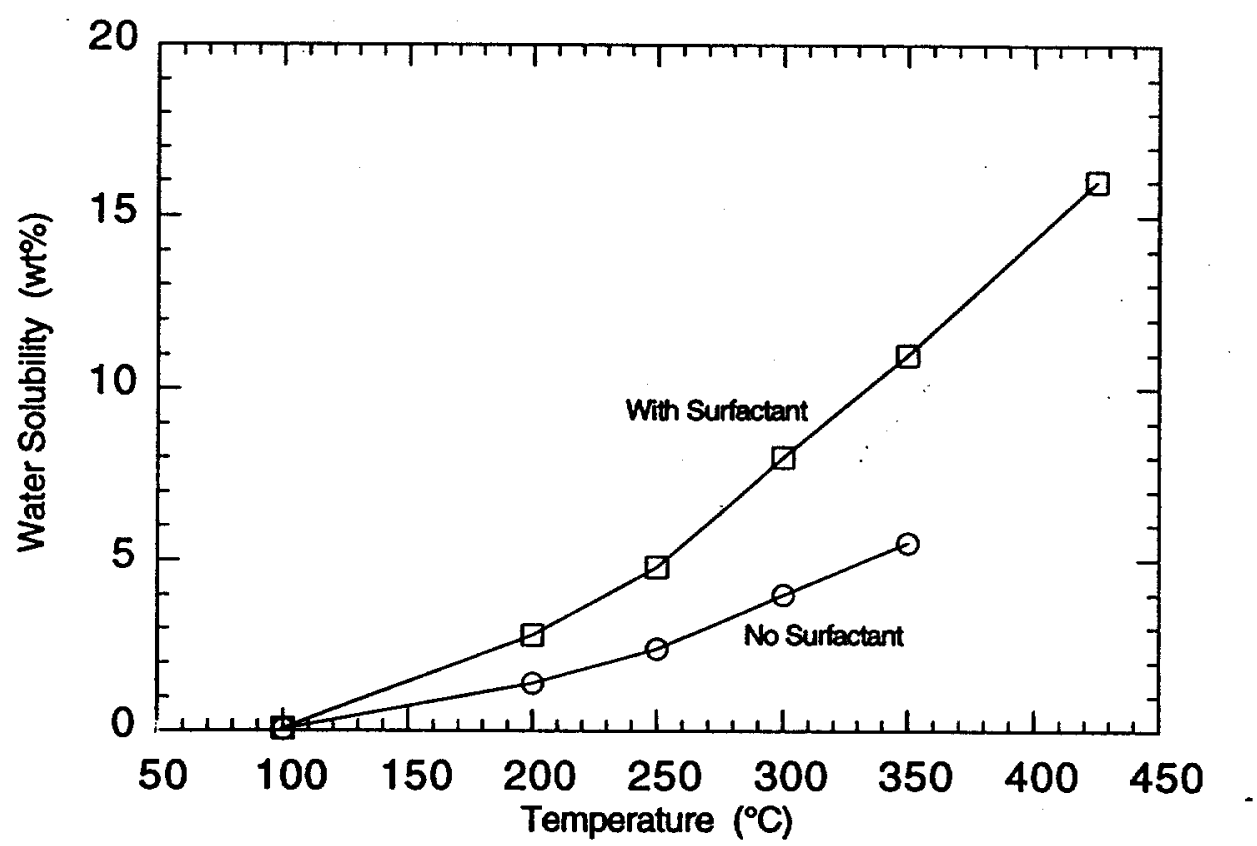

Figure 7. Water solubility in oil for surfactant and nonsurfactant systems 


\section{REACTION EXTENT - GAS AND COKE PRODUCTION}

The amounts of coke and gas produced are both important measures of the extent of pyrolysis that has occurred. They are also important since they represent potential oil loss to any upgrading process. In addition, vapor evolution can play an important role in determining the system pressure. Unfortunately, experimental complications prohibit directly measuring these parameters. It is difficult to obtain unambiguous coke measurements from the final product because of separation and collection problems. The gas evolution measurements are complicated by condensation and solubility of vapors at low temperatures and the presence of large water partial pressures at elevated temperatures.

Probably the simplest way to deal with the vapor equilibria problem is to assume that the only products of pyrolysis are coke and species which can be detected in the vapor phase at the end of the experiment. Although this assumption neglects, for now, the production of oil components, it allows a useful first look at the pressure temperature behavior of the system, particularly at modest temperatures. The gas species, detected by GC analysis, include hydrogen, carbon dioxide, carbon monoxide, hydrogen sulfide, methane, ethane, ethylene, propanes, and butanes.

A simple model was constructed using the ASPEN PLUS commercial simulation package to look at the end state of the system. The ASPEN PLUS simulator is primarily tailored for continuos processes. However, through proper choice of modules and other specifications it can be made to simulate the end point, or other selected intermediate points in the batch autoclave experiments. ASPEN PLUS was used for this purpose because it has a rich variety of property models, several of which are tailored for use in hydrocarbon systems. In addition, we plan to use this process simulator package to develop a process model for aqueous pyrolysis.

A listing of the ASPEN PLUS model in ASPEN PLUS input language is given in Appendix III. Several property models available in ASPEN PLUS were explored, but final calculations were done using the GRAYSON property set. This property set was developed for hydrocarbon and light gas containing systems. It is applicable to temperatures between 200-700 $\mathrm{K}$ and pressures below 21.3 MPa. It uses the GraysonStreed correlation for reference state fugacity coefficients and the ScatchardHilderbrand model for activity coefficients. The Redlich-Kwong equation is used for vapor fugacities.

The model is setup so that for a given assumption about the pyrolysis stoichiometry, extent of reaction and system temperature, vapor and liquid compositions are computed which satisfy the desired mixture density. This leads to a computed system pressure. The mixture density is established by the amount of feed to the autoclave and the autoclave volume. For each run in which significant system pressure was left after cool down a set of stoichiometric parameters were determined using the ASPEN PLUS model which yielded a fit to the gas composition at the end of the cool-down period. 
In doing the fit, carbon monoxide was not included since it appeared in only four of the runs and was at low levels. Also hydrocarbon species above methane were lumped into a single alkane species for each carbon number. Although there is the possibility of the water-gas-shift reaction occurring and involving some of the water, it was not explicitly included as a reactant. The temperatures are fairly low and the amount of hydrogen and carbon monoxide production in the runs was relatively low. The crude oil was modeled with five pseudocomponents as described previously.

Table 4 list the results of the fitting procedure. The reaction extent is measured as a fraction of initial crude oil which has reacted. The coke fraction is a weight fraction of reacted oil which ends up as coke. In the analysis, coke was assumed to be pure carbon. The gas stoichiometry is given as ratios to methane production. The total assumed weight of gas is given by the product of the reaction extent and one minus the coke fraction. The term gas is used here as shorthand for light components produced by the pyrolysis. All these components are not in the gas after the cool-down period. For example, for Run 126, the percentages of each component computed to be in the vapor phase at the end of the cool-down period, when the autoclave conditions were $25^{\circ} \mathrm{C}$ and $2.38 \mathrm{MPa}$, were the following: $\mathrm{CO}_{2}-63 \%, \mathrm{H}_{2} \mathrm{~S}-22 \%$, $\mathrm{H}_{2}-98 \%, \mathrm{CH}_{4}-78 \%, \mathrm{C}_{2}$ 's $-44 \%, \mathrm{C}_{3}$ 's $-21 \%$, and $\mathrm{C}_{4}$ 's $-6 \%$.

Table 4. Estimate of extent of reaction, coke fraction and gas stoichiometry for runs with significant gas FE-III production grouped according to catalyst present.

\begin{tabular}{|c|c|l|lllllll|}
\hline & Reaction & Coke & \multicolumn{7}{|c|}{ Gas Stoichiometry } \\
Run & Extent & Fraction & $\mathrm{CO}_{2}$ & $\mathrm{H}_{2} \mathrm{~S}$ & $\mathrm{H}_{2}$ & $\mathrm{CH}_{4}$ & $\mathrm{C}_{2}{ }^{\prime}$ s & $\mathrm{C}_{3}$ 's & $\mathrm{C}_{4}$ 's \\
\hline 120 & 0.040 & 0.500 & 0.305 & 0.200 & 0.130 & 1.000 & 0.352 & 0.320 & 0.130 \\
122 & 0.047 & 0.470 & 0.217 & 0.104 & 0.107 & 1.000 & 0.356 & 0.320 & 0.280 \\
126 & 0.115 & 0.480 & 0.121 & 0.062 & 0.025 & 1.000 & 0.390 & 0.269 & 0.150 \\
6 & 0.043 & 0.470 & 0.225 & 0.126 & 0.107 & 1.000 & 0.323 & 0.255 & 0.190 \\
29 & 0.122 & 0.540 & 0.100 & 0.000 & 0.058 & 1.000 & 0.296 & 0.152 & 0.120 \\
\hline
\end{tabular}

Mo

\begin{tabular}{|c|c|l|lllllll|}
\hline & Reaction & Coke & \multicolumn{7}{|c|}{ Gas Stoichiometry } \\
Run & Extent & Fraction & $\mathrm{CO}_{2}$ & $\mathrm{H}_{2} \mathrm{~S}$ & $\mathrm{H}_{2}$ & $\mathrm{CH}_{4}$ & $\mathrm{C}_{2}{ }^{\prime} \mathrm{s}$ & $\mathrm{C}_{3}$ 's & $\mathrm{C}_{4}$ 's \\
\hline 106 & 0.039 & 0.300 & 0.180 & 0.000 & 0.063 & 1.000 & 0.400 & 0.380 & 0.400 \\
112 & 0.052 & 0.440 & 0.290 & 0.120 & 0.087 & 1.000 & 0.380 & 0.410 & 0.460 \\
116 & 0.147 & 0.520 & 0.148 & 0.030 & 0.054 & 1.000 & 0.386 & 0.290 & 0.200 \\
\hline
\end{tabular}

Co

\begin{tabular}{|c|c|l|lllllll|}
\hline & Run & Extent & Coke & \multicolumn{7}{|c|}{ Fraction } & $\mathrm{CO}_{2}$ & $\mathrm{H}_{2} \mathrm{~S}$ & $\mathrm{H}_{2}$ & $\mathrm{CH}_{4}$ & $\mathrm{C}_{2}{ }^{\prime} \mathrm{s}$ & $\mathrm{C}_{3}$ 's & $\mathrm{C}_{4}$ 's \\
\hline 114 & 0.072 & 0.450 & 0.225 & $\mathbf{0 . 0 2 4}$ & 0.028 & 1.000 & 0.401 & 0.393 & 0.330 \\
10 & 0.064 & 0.420 & 0.214 & 0.024 & 0.160 & 1.000 & 0.365 & 0.368 & 0.330 \\
14 & 0.094 & 0.685 & 0.172 & 0.000 & 0.396 & 1.000 & 0.262 & 0.197 & 0.130 \\
18 & 0.038 & 0.330 & 0.225 & 0.008 & 0.295 & 1.000 & 0.326 & 0.278 & 0.140 \\
\hline
\end{tabular}


Although results are shown for all the catalysts, the current focus is on Fe-III. More runs were done with this catalyst and as a result the remaining analysis related to stoichiometry and kinetics will deal only with the Fe-III runs. Analysis of the Fe-III runs show a remarkably consistent coke fraction averaging about 0.5 . There is no trend in coke yield, as a fraction of total oil reacted, with extent of reaction. The gas stoichiometry is not as consistent as the coke yield. There appears to be some trend in fraction of hydrogen and carbon dioxide with extent of reaction. The data suggest that at higher conversions these two components tend to make up a lower fraction of total gas production. The $\mathrm{C}_{2}$ 's remain very consistent from run to run. Less consistency is seen in the other components, with the highest variation in the $\mathrm{H}_{2} \mathrm{~S}$ fraction.

An average stoichiometry was obtained from the Fe-III data and is listed in Table 5. Run 29 was omitted from the average because $\mathrm{H}_{2} \mathrm{~S}$ was not reported. This stoichiometry was arrived at assuming that the listed components are the only reaction products. Undoubtedly, other components are formed but are too heavy to show up in any significant way in the vapor phase at room temperature. However, some information can be obtained from the changes in API gravity of the oil. This information can be used to speculate about additional changes occurring during the pyrolysis reactions.

Table 5. Average reaction stoichiometry.

\begin{tabular}{|cccc|}
\hline & $\begin{array}{c}\text { Weight } \\
\text { Fraction }\end{array}$ & $\begin{array}{c}\text { Gas - Ratio } \\
\text { with CH4 } \\
\text { (mol/mol) }\end{array}$ & $\begin{array}{c}\text { Gas - Ratio with } \\
\text { Total Gas } \\
\text { (mol/mol) }\end{array}$ \\
\hline Coke & 0.5 & & \\
& & & \\
$\mathrm{CO}_{2}$ & 0.070 & 0.19 & 0.088 \\
$\mathrm{H}_{2} \mathrm{~S}$ & 0.034 & 0.12 & 0.055 \\
$\mathrm{H}_{2}$ & 0.0015 & 0.09 & 0.041 \\
$\mathrm{CH}_{4}$ & 0.133 & 1 & 0.461 \\
$\mathrm{C}_{2}$ 's & 0.085 & 0.34 & 0.157 \\
$\mathrm{C}_{3}$ 's & 0.095 & 0.26 & 0.120 \\
$\mathrm{C}_{4}$ 's & 0.082 & 0.17 & 0.078 \\
\hline
\end{tabular}

The simplest method of incorporating the change of API gravity into a consideration of overall reaction stoichiometry is to make the simplifying assumption that, in addition to the components already listed, a single relatively light oil is a product of the pyrolysis of the crude oil. To further simplify the system it is assumed that the ratio of this new oil to production of other components is fixed. With these assumptions and the ASPEN PLUS model, computations were done in which the relative amount and nature of the light product oil was adjusted in an effort to obtain the best fit for the measured API gravities for the Fe-III experiments. The results are shown in 
Table 6. The light oil component used was a pseudocomponent with a molecular weight of 109 amu and an API gravity of $45^{\circ}$. This component was generated by ASPEN PLUS as one of the potential cuts for describing a crude oil representing the oil fraction with an average boiling point of $121^{\circ} \mathrm{C}$. This cut is the next lightest below those present in the feed crude. An even lighter cut was tried, having a molecular weight of about $76 \mathrm{amu}$. However, this component had enough volatility that upon reduction of pressure to atmospheric levels insufficient material was computed to remain in the liquid to yield the measured API gravity changes.

Table 6. Computed oil gravity assuming a weight fraction light oil production of 0.6 . The feed crude had an API gravity of 13.5 .

\begin{tabular}{|ccc|c|}
\hline Run & $\begin{array}{c}\text { Measured } \\
\text { API Gravity }\end{array}$ & $\begin{array}{c}\text { Computed } \\
\text { API Gravity }\end{array}$ & $\begin{array}{c}\text { Reaction } \\
\text { Extent }\end{array}$ \\
\hline 108 & 17.5 & 18.1 & 0.161 \\
120 & 16.8 & 16.5 & 0.112 \\
122 & 17.9 & 17.3 & 0.129 \\
126 & 22.0 & 22.3 & 0.340 \\
6 & 17.0 & 16.9 & 0.118 \\
29 & not available & 23.4 & 0.355 \\
\hline
\end{tabular}

It was assumed that the oil used in the gravity measurements was represented by the liquid which would result from flashing the final mixture to one atmosphere and separating out the coke and free-water phase. Note this assumes the vapor above the oil is light gases. This is equivalent to assuming that the sample was kept in a sealed container after depressurization and large amounts of air were not swept over its surface.

The match of measured gravities with this simple model is remarkably good. However, the addition of this somewhat volatile component has the potential for altering the final equilibrium pressure. This is a result of added volatility, but more importantly the change in the liquid properties. This effect was reasonably small and was compensated for by readjusting the reaction extent. The reaction extent used is listed in Table 6. Most of the difference in reaction extent between those reported in Tables 4 and 6 is a result of the introduction of a major new product of the reaction, the light oil, and not the minor change in phase equilibria. The adjustment to reaction extent to compensate for changes in equilibria was only a few percent.

So far the issue of reaction rate has not been addressed. Clearly, the actual changes occurring are very complex and the simplified stoichiometry used above, and any simple kinetic expressions based on them, are rough engineering approximations. However, rough engineering approximations are useful in helping to describe conditions for a proposed process. The simplest rate expression that has a chance of capturing some aspects of the true behavior is one based on the assumption that all 
components of the feed oil decompose at the same rate and with the same basic stoichiometry when viewed on a weight basis. If this is true, then the reaction rate for experiments should be roughly constant at a given temperature since the estimated extent of the reactions, as a fraction of original oil, is fairly small.

One way to test this hypothesis is to look at the pressure behavior of the runs during the plateau temperature period. Since light gases are assumed to be products of reaction, one would expect that the pressure of the system would increase with time in some linear fashion. The details of the relation between pressure increase and light-gas production is complicated and will be addressed below. However, here it is useful to determine if the pressure increases are linear during the plateau period. The plots shown in Fig. 8 do indeed indicate a near linear increase in pressure during the plateau period, even for Runs 126 and 29 in which the extent of reaction is as high as $36 \%$. 

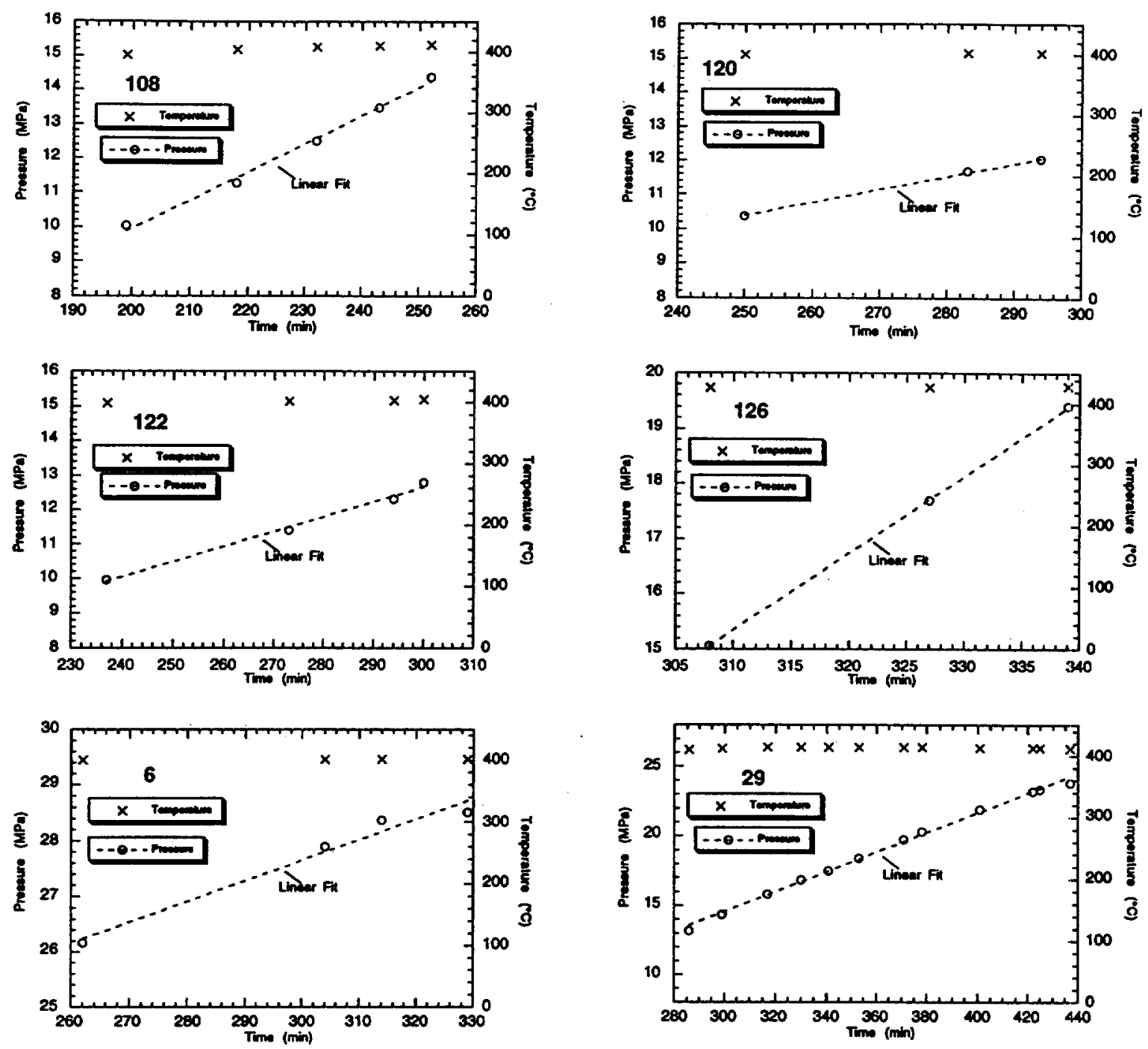

Figure 8. Plateau period of the Runs $108,120,122,126,6$ and 29 demonstrating the near linear increase in autoclave pressure.

The ACS model was developed to allow rate controlled gas release to be incorporated into the modeling of change within a sealed autoclave. This model was used to integrate the proposed simple first-order reaction over the course of the heating and cooling sequence of those Fe-III experiments in which significant pyrolysis occurred. The assumed reaction stoichiometry was that described above, including the production of light oil. The overall stoichiometry used is listed in Table 7. Other model parameters used relating to densities and phase equilibria are given in Appendix IV. 
Table 7. Average reaction stoichiometry including the light oil product $\mathrm{P}-\mathrm{O}$.IL.

\begin{tabular}{|cc|}
\hline & $\begin{array}{c}\text { Weight } \\
\text { Fraction }\end{array}$ \\
\hline Coke & 0.2 \\
P-OIL & 0.6 \\
& 0.028 \\
$\mathrm{CO}_{2}$ & 0.014 \\
$\mathrm{H}_{2} \mathrm{~S}$ & 0.0006 \\
$\mathrm{H}_{2}$ & 0.053 \\
$\mathrm{CH}_{4}$ & 0.034 \\
$\mathrm{C}_{2}$ 's & 0.038 \\
$\mathrm{C}_{3}$ 's & 0.033 \\
$\mathrm{C}_{4}$ 's & \\
\hline
\end{tabular}

The pre-exponential kinetic values which best fit the coke yield data for the Fe-III runs are listed in Table 8 along with the computed reaction extent for each run. These were found using the average stoichiometry given in Table 7 and adjusting the pre-exponential rate factor until the best fit of the final autoclave pressure, oil gravity and coke production were obtained. The values of the factors determined in this way are fairly consistent from run to run. An extent-weighted average of these values yields an value of $1.7 \times 10^{8} \mathrm{~s}^{-1}$.

Table 8. ACS determined rates and computed extent of reaction.

\begin{tabular}{|ccc|}
\hline Run & $\begin{array}{c}\text { Pre-Exponential } \\
\left(\mathrm{s}^{-1}\right)\end{array}$ & $\begin{array}{c}\text { Reaction } \\
\text { Extent }\end{array}$ \\
\hline 108 & $1.89 \times 10^{8}$ & 0.145 \\
120 & $1.29 \times 10^{8}$ & 0.099 \\
122 & $1.36 \times 10^{8}$ & 0.110 \\
126 & $1.93 \times 10^{8}$ & 0.325 \\
6 & $1.45 \times 10^{8}$ & 0.109 \\
29 & $1.84 \times 10^{8}$ & 0.368 \\
\hline
\end{tabular}

Since detailed analytical information on the crude oil and products is limited, no attempt in the modeling was explicitly made to guarantee individual atom balances, only overall weight balances are used. However, it is of interest to determine the results of an atom balance based on the stoichiometry shown in Table 7. Analytical data is only available for the sulfur content of the crude oil. Using this number and average values for crude oils from reference 7 , in addition to values for the P-OIL product which fall within the range for crude oils (see Table 9), atom balances on carbon, hydrogen, and sulfur were computed. Nitrogen is omitted from the balance since no information on nitrogen bearing products was available. The carbon and hydrogen were balanced by using the atomic composition of oils shown in Table 9. 
For oxygen, the balance indicates an excess of oxygen in the product mix. This is attributed to water which enters the reaction as a reactant during secondary reactions such as would occur in the water-gas-shift reaction. The amount of water consumed based on the average stoichiometry would be equal to approximately $4-5 \mathrm{wt} \%$ of the feed for runs with the highest extent of reaction.

Table 9. Oil atomic composition in weight percent.

\begin{tabular}{|c|c|c|c|c|}
\hline & $\mathrm{C}$ & $\mathrm{H}$ & 0 & $S$ \\
\hline $\begin{array}{l}\text { CRUDE } \\
\text { P-OIL }\end{array}$ & $\begin{array}{l}85.46 \% \\
85.10 \%\end{array}$ & $\begin{array}{l}12.00 \% \\
14.00 \%\end{array}$ & $\begin{array}{l}1.00 \% \\
0.05 \%\end{array}$ & $\begin{array}{l}1.54 \% \\
0.40 \%\end{array}$ \\
\hline
\end{tabular}

\section{COMPUTED PRESSURE MATCHES-RUNS WITH REACTION}

Using the average stoichiometry given in Table 7 and the average rate model which is given by

$$
\text { rate }=W_{\text {crude }} 1.7 \times 10^{8} \exp \left(\frac{-20000}{T}\right)
$$

where $W_{\text {crude }}$ is the amount of crude oil in the liquid phase and the rate is given on a weight-per-second basis, computations were performed to look at the time evolution of the pressure within the autoclave during experiments in which significant gas was produced. Results are shown in Fig. 9 for runs with highest gas evolution, runs 126 and 29 . Run 126 reached a maximum temperature of $429^{\circ} \mathrm{C}$ while run 29 was held at $413^{\circ} \mathrm{C}$, but the temperature in run 29 was held longer so that the total reaction extent was approximately the same. The calculations were done with the original water solubility curve, for the case in which a surfactant is present, shown in Fig. 7. Notice, that during the active reaction period, the time at highest temperature, the model under predicts the rate of increase in pressure.

Some work was done to determine why the model under predicts this rise. Two candidate reasons are that the equilibrium relations change in a fashion not captured by the model or that a component is formed which appears in the vapor phase at elevated pressures but is absent from the vapor when the system is cooled. The component P-OIL behaves in this way and is present in the model used to develop the curves shown in Fig. 9. Other model products such as pentane, toluene, and $n$-decane were included in the reaction scheme. None seem to significantly improve the fit at the peak pressures.

However, some improvement in the pressure fit was found when the water solubility relation was modified to allow more water to enter the vapor phase at the higher temperatures. A modified solubility was developed which incorporated this effect and was used to compute the improved pressure matches for Experiments 126 and 29 shown in Fig. 10. The solubility modification simply involved not extrapolating the solubility curve, shown in Fig. 7, linearly for temperatures beyond 
$350^{\circ} \mathrm{C}$, but instead setting the solubility at $430^{\circ} \mathrm{C}$ to $9 \mathrm{wt} \%$. This change in solubility should be viewed as a means of changing the activity of the water in the oil phase. The solubility in conjunction with the simple activity coefficient model described previously sets the fugacity of the water dissolved in the oil and, thus, the fugacity of water vapor in the gas phase.
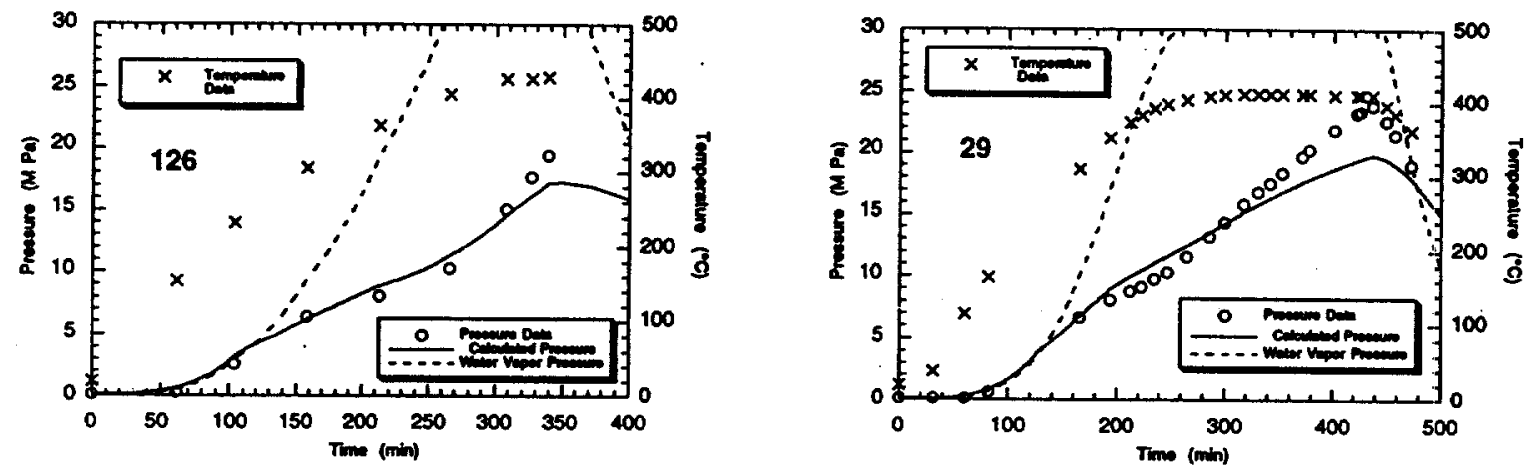

Figure 9. ACS calculated pressures using average stoichiometry and average expression.
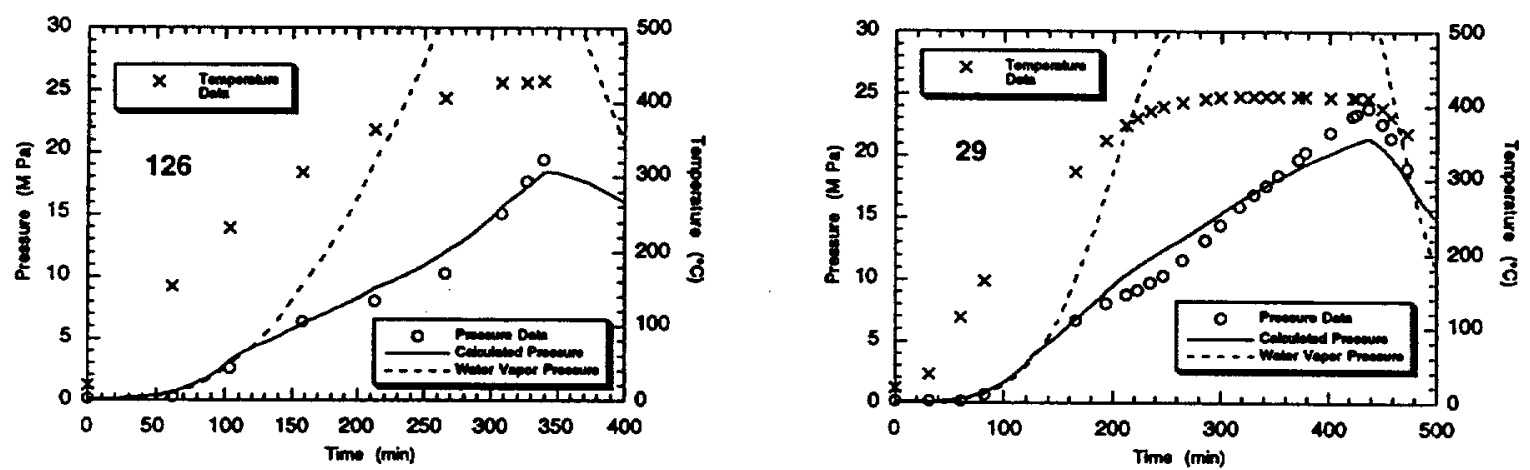

Figure 10. ACS calculated pressures using average stoichiometry and average expression with a flattened water solubility curve.

One of the ultimate aims of the current work is to develop an ASPEN PLUS based model for the proposed upgrading process. For this reason, and because of the more sophisticated property models available in the ASPEN PLUS environment, it is of interest to compare ASPEN PLUS computations to the data and the ACS model results. For this purpose, the final overall ACS model which included a flattening of the solubility model was used.

In ASPEN PLUS, the solubility model is forced to have the following form with respect to temperature

$$
s=\exp \left(c_{1}+\frac{c_{2}}{T}+c_{3} T\right)
$$


where $s$ is the solubility of water in oil on a mole fraction basis, and the $c^{\prime} s$ are coefficients specific to each oil component used. This constraint does not allow exactly the same solubility function to be used in both the ACS model and ASPEN PLUS model. However, the parameters $c_{1}=24.35, c_{2}=-8000$, and $c_{3}=-0.019$ gives computed points similar to those used in the ACS model calculations, these are compared in Table 10. In the table, a molecular weight of 389 amu was used in computing the values. This is the average value for the crude oil based on the pseudocomponent representation used. As describe earlier, the ACS uses a solubility model which is based simply on total weight of oil and water in the oil phase. Using the same coefficients for all crude oil components in the ASPEN PLUS model along with the average stoichiometry given above, pressures where computed at several reaction times for runs 126 and 29. The reaction extent was taken from results computed by the ACS model. Fig. 11 shows that the computed pressure results obtained from the ASPEN PLUS model and the ACS model are very similar. Both do a fair job in computing the autoclave pressures.

Table 10. A comparison of water solubility used in the ASPEN PLUS model and the ACS model.

\begin{tabular}{|ccc|}
\hline $\begin{array}{c}\text { Temperature } \\
\left({ }^{\circ} \mathrm{C}\right)\end{array}$ & $\begin{array}{c}\text { ASPEN PLUS } \\
\text { Water (wt\%) }\end{array}$ & $\begin{array}{c}\text { ACS } \\
\text { Water (wt\%) }\end{array}$ \\
\hline 25 & $0.0 \%$ & \\
50 & $0.0 \%$ & \\
100 & $0.1 \%$ & $0.1 \%$ \\
150 & $0.4 \%$ & \\
200 & $1.2 \%$ & $2.8 \%$ \\
250 & $3.2 \%$ & $4.8 \%$ \\
300 & $6.7 \%$ & $8.0 \%$ \\
350 & $10.6 \%$ & $11.0 \%$ \\
400 & $10.8 \%$ & \\
425 & $9.3 \%$ & $9.0 \%$ \\
\hline
\end{tabular}
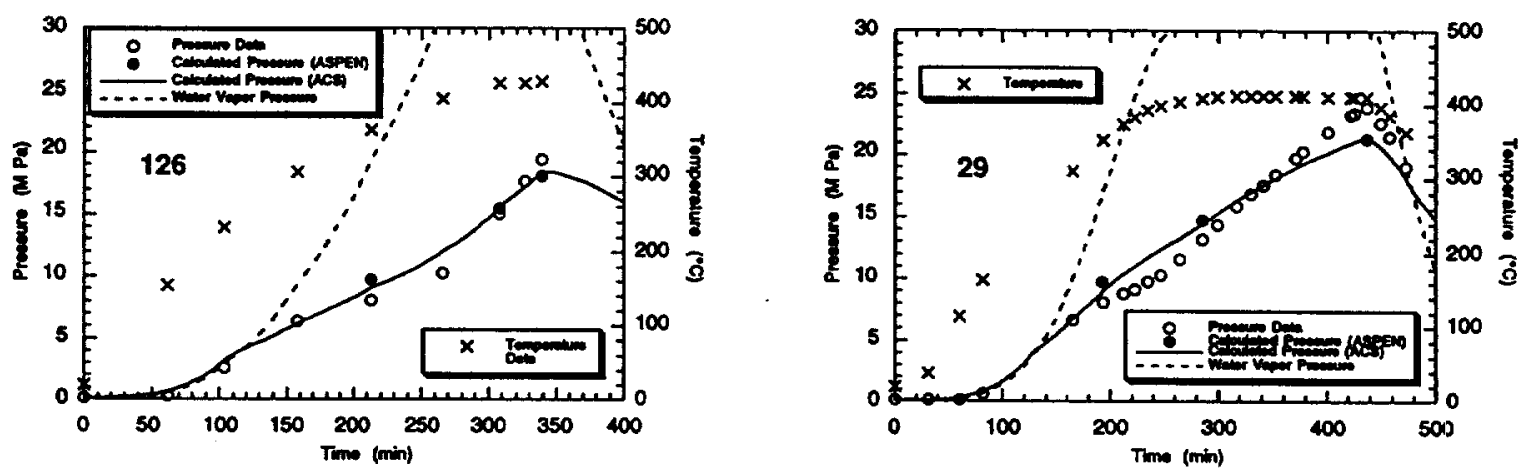

Figure 11. Pressures computed using the ASPEN PLUS model compared to experimental data and results from the ACS model for runs 126 and 29. 


\section{CONCLUSIONS}

Data and modeling work show that autoclave pressures for heavy-crude oil/water systems can exhibit total pressures well below the vapor pressure of water at conditions in which not all the water is in the vapor phase. This is a result of increased solubility of water in the oil phase at elevated temperatures. Further, pressure measurements indicate that the presence of a surfactant increases the apparent solubility. A simple water-in-oil activity coefficient model was used to fit pressure responses for autoclave experiments.

Autoclave aqueous pyrolysis runs in which temperatures of $400^{\circ} \mathrm{C}$ or above were reached exhibited measurable gas production. This gas production resulted in pressure increases during periods of constant temperature. These pressure increases were remarkably linear with time. A simple first-order decomposition is consistent with such a response if essentially all the original crude oil undergoes similar pyrolysis decomposition. A first-order reaction model was constructed for the runs in which Fe-III was used as a catalyst. The model did a fair job in matching gas and coke production as well as change in oil gravity.

The first-order reaction model was used in a model developed to look at the evolution of pressure within an autoclave with time. Also, an ASPEN PLUS based model gave similar results for selected points. The models tend to under predict the rate of pressure rise with time at the plateau temperatures. A number of different reaction products were postulated in an attempt to overcome this deficiency. These attempts met with little success. The one parameter which seemed to improve the performance was to assume that at temperatures above $350-400^{\circ} \mathrm{C}$, the activity coefficient of water in oil increased, releasing more water vapor into the vapor phase. This was modeled as a decrease in water solubility in the oil phase.

Although the simple reaction model did a fair job in recreating the pressure history of the autoclave experiments, more work is probably warranted. In particular, the problem of matching the isothermal pressure rise needs further exploration, as does the cause of variability in measured gas composition. If the measured gas composition variation persists, a more complicated reaction scheme than the simple one-step pyrolysis reaction used here will be necessary. A more complicated reaction scheme may also help resolve the isothermal pressure rise problem. Also a better model for the activity of water in the oil phase would be required to improve predictive capability. Finally, post-run analysis of the change in the makeup of the oil phase would probably help in formulating a better model for the improvement in oil gravity. This may also help in understanding the vapor-liquid equilibrium behavior. 


\section{REFERENCES}

1. J. G. Reynolds, A. M. Murray, E. V. Nuxoll, and G. A. Fox, "Upgrading of Heavy Oil from the San Joaquin Valley of California by Aqueous Pyrolysis," Lawrence Livermore National Laboratory, Livermore, CA, UCRL-122472 (1995).

2. H. H. Hooper, S. Michel, and H. M. Prauznitz, Correlation of Liquid-Liquid Equilibria for Some Water-Organic Liquid Systems in the Region 20-250 ${ }^{\circ} \mathrm{C}$, Ind. Eng. Chem. Res. 27, pp. 2182-2187, (1988).

3. C. B. Thorsness "A Model for Simulating Autoclave-Reactor Pressure Histories," Lawrence Livermore National Laboratory, Livermore, CA, UCRL-ID-122947 (1995).

4. R. C. Reid, J. M. Prauznitz, B. E. Poling, The Properties of Gases and Liquids, Fourth Edition, (McGraw-Hill Book Company, New York, 1987) pp. 284-286.

5. R. C. Reid, J. M. Prauznitz, B. E. Poling, The Properties of Gases and Liquids, Fourth Edition, (McGraw-Hill Book Company, New York, 1987) pp. 205-206.

6. ASPEN PLUS Reference Manual - Volume 2 - Physical Property Methods and Models, (Aspen Technology, Inc., Cambridge, Massachusetts, 1994) Chapter 3 p. 101, Chapter 6 pp. 3-5.

7. J. G. Speight, Ed., Fuel Science and Technology Handbook, (Marcel Dekkar, Inc., New York, 1990) pp. 209-210. 


\section{APPENDIX I.}

\section{CRUDE OIL DATA}

Selected data for Midway Sunset crude Oil analyzed by Core Laboratories:
API Gravity
Pour Point
$11.8^{\circ}\left(60 / 60^{\circ} \mathrm{F}\right)$
$+60^{\circ} \mathrm{F}$ ASTM-D-97)
Sediment and water $5.6 \mathrm{wt} \%$ (ASTM D-96)
Sulfur, Total by $\mathrm{x}$-ray $1.54 \mathrm{wt} \%$ (ASTM D-4294)

Cuts
1. IBP-375 ${ }^{\circ} \mathrm{F}$
2. $375-500^{\circ} \mathrm{F}$
3. $500-620^{\circ} \mathrm{F}$
371.1
29.9
0.87
23.7
5.36
4. $620-800^{\circ} \mathrm{F}$
16.0
10.8
5. $800-950^{\circ} \mathrm{F}$
6. $950+{ }^{\circ} \mathrm{F}$
13.8
14.79
21.94
$4.6 \quad 46.08$

API Gravity $\quad W t \%$

This information along with boiling point curves for each cut were used to determine the pseudocomponent properties and amounts given in the report. The analysis above is actually from oil which has undergone surface dewatering and the loss of some light ends. To arrive at the final weight distribution given in the report, the lighter ends were increased until the mixture had an API gravity of $13.5^{\circ}$ - approximately equivalent to that used in the laboratory experiments. The increases used preserved the monotonic nature of component amounts with API gravity. 


\section{APPENDIX II.}

\section{WATER-NITROGEN SYSTEM}

Two autoclave runs were done with a water nitrogen system to help evaluate the ability of the ACS model to compute autoclave pressures. The first run, \#32, was a system with excess water. The amount of water initially in the $1050 \mathrm{~cm}^{3}$ autoclave, $0.3 \mathrm{~kg}$, insured that liquid would be present up to the critical point. In the second run, \#34, a much smaller amount of water, $0.033 \mathrm{~kg}$, was used. In this case liquid disappeared before reaching the critical point. For both runs, the system was initially pressurized at room temperature to approximately $1.6 \mathrm{MPa}$ with nitrogen.

In Fig. II-1 computed pressures for Run 32 are compared to measured autoclave pressures. The Redlich-Kwong equation of state was used to compute gas phase fugacities. Results using the ideal gas law yielded similar pressure results.

However, the computations using the Redlich-Kwong equation result in twice as much water in the vapor phase as is the case for the assumption of ideal behavior. This is primarily a result of the more accurate gas phase density estimates provided by this equation. The Redlich-Kwong results estimate a gas phase compressibility of 0.57 at $358^{\circ} \mathrm{C}$.

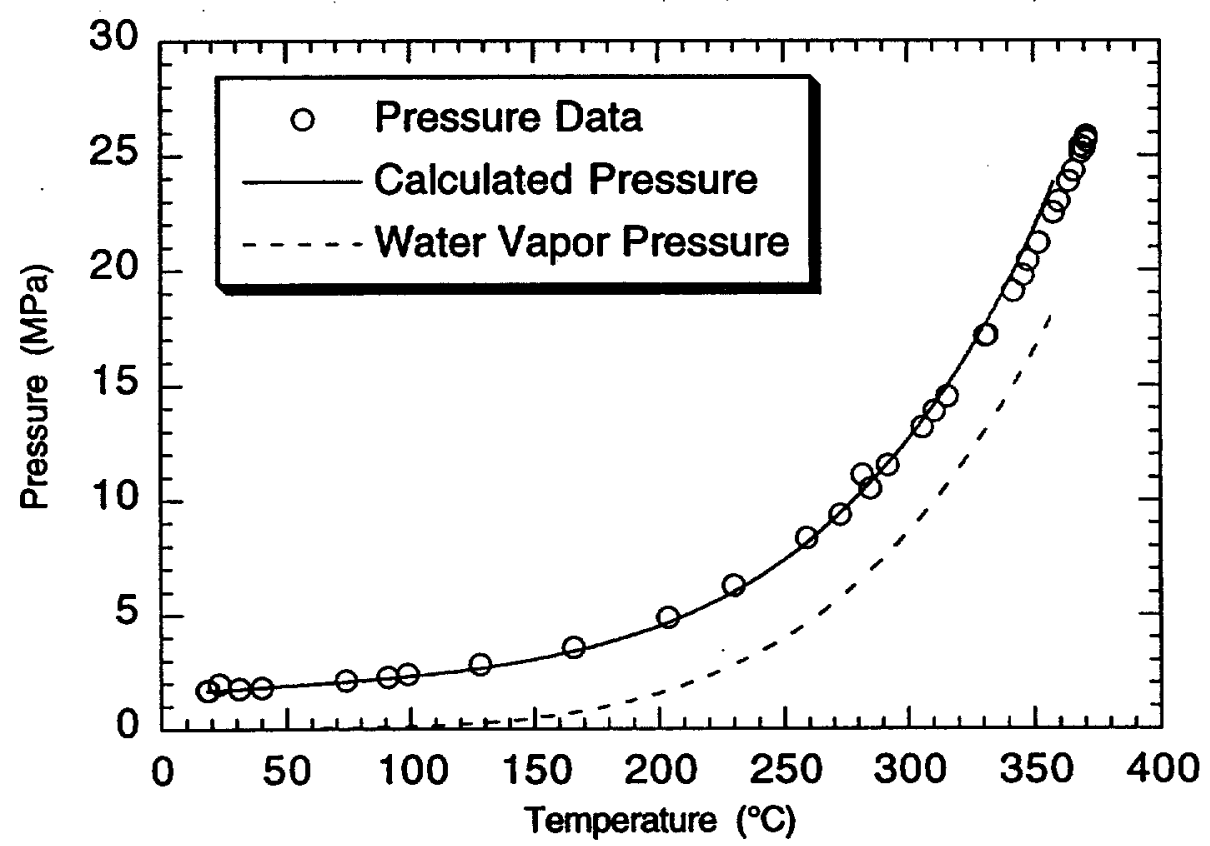

Figure II-1. Computed pressure for run 32 using the ACS model and the Redlich-Kwong equation of state for gas phase fugacities. 
In Fig. II-2 results for Run 34 are plotted. Here the pressure response based on the Redlich-Kwong equation differs from that obtained assuming ideal gas behavior. This is because liquid disappears and as a result predicting the amount of water in the vapor phase influences the computed pressure directly.

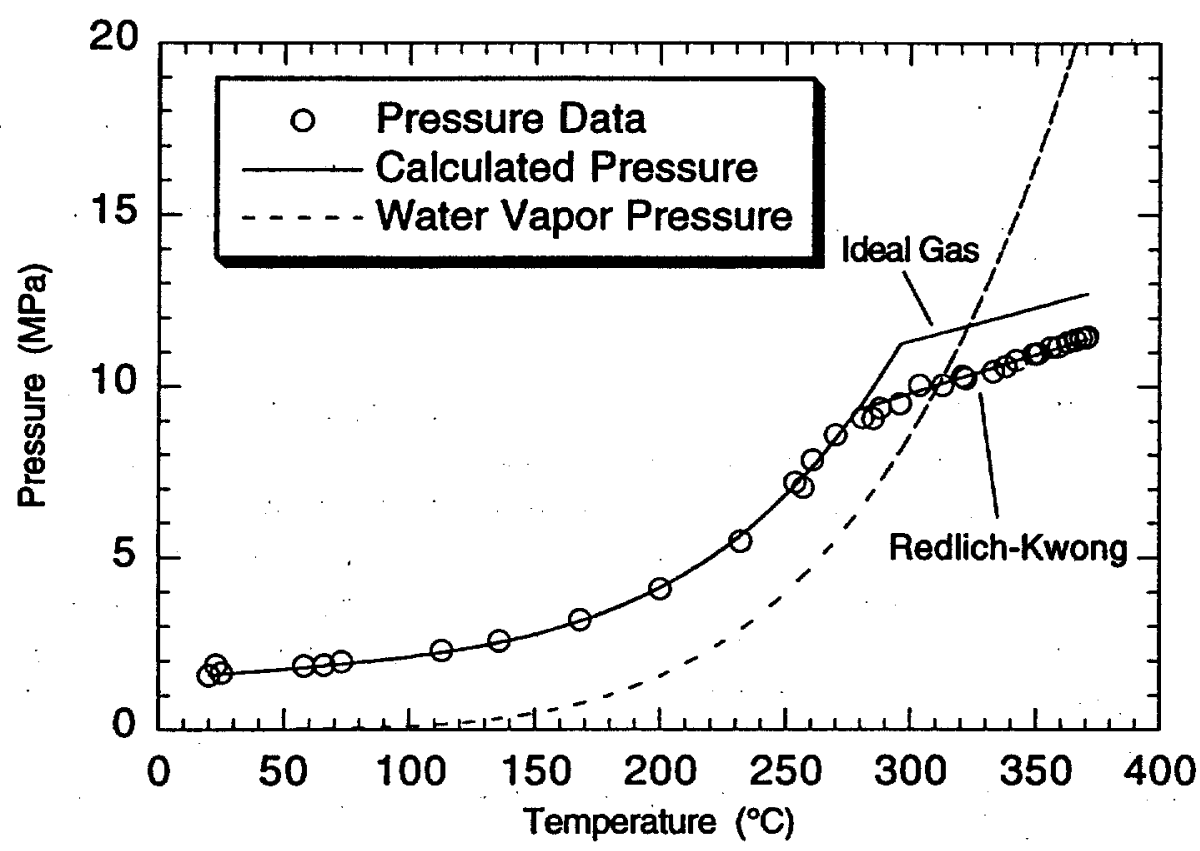

Figure II-2. Computed pressure for run 34 using the ACS model and the Redlich-Kwong equation of state and the ideal gas law for gas phase fugacities.

For both runs the ACS model using the Redlich-Kwong equation does a fairly good job in calculating the autoclave pressure as a function of temperature. 


\section{APPENDIX III.}

\section{ASPEN MODEL}

The ASPEN PLUS model described below was used to look at selected states of the autoclave system. It allows three separate states of the system to be computed in one run. The basic philosophy is to use other means to establish the extent of any reactions which occur. This information along with initial conditions are then used to compute the pressure of the autoclave system. The pressure is determined by using an ASPEN PLUS DESIGN-SPEC to set the total density of the autoclave. This density is known from initial loading information.

The basic design of the model relies on two input files. The first is an ASPEN PLUS input file which defines the model. The second file is an ASCII data file to define the parameters specific to a run. The model is structured in this way for two reasons. One reason is to allow repeated runs to execute faster. Although the computation time for the model on an HP-9000/730 is less than a minute, even this time can be annoying when many runs are to be done. By isolating the basic run specific data, the ASPEN PLUS's rerun option can be employed which greatly speeds up execution. The other reason, probably more important, is to allow documentation of runs to be maintained in a more economical fashion and allow model revisions to be made with a minimum of effort. If the basic run data is put directly into the input file then when a revision in the model structure is made, these same modifications must be made in all input files representing other runs. With the basic structure of the model specified by a single input file and the run data separated, only one file needs to be changed to modify the model. Also the run data information is only about 50 lines including generous commenting, while the ASPEN PLUS input file was 1300 lines long.

The description of the model will assume that the reader is familiar with the ASPEN PLUS input language. A complete listing of the model with line numbers is given at the end of this appendix along with a sample input file.

The model is broken into four flowsheets. This is done to allow for the possibility of using different property models in different flowsheet sections. The first three are very similar and use MIXER, FLASH2 and RSTOIC modules to perform the required calculations. Each of these flowsheets works on a separate, but identical, feed stream. The feed streams are meant to represent the material loaded into the autoclave reactor. The simulator is most naturally a continuous flow simulator and the autoclave is a closed system. To simulate the closed system the ratio of flow rates of input maierial is set so to give the proper ratios and set at levels such that one second of time yields the same quantity of material as is in the autoclave. The fourth flowsheet section is used to simulate what occurs when the autoclave is depressurized. This section uses results from flowsheet three as input.

Consequently, to be meaningful the state of the outlet of flowsheet three should be 
equivalent to the end state of the system after cool down and just prior to depressurising.

The following discussion refers to the listing of the ".inp" file located near the end of this appendix. At the start of the file are a number of comment lines and a run title.. Starting on line 25 is the FORTRAN block SETI. This block is used to read input data from the ASCII input file, do some calculations, and then set parameters in computational modules. These parameters include input flow rates as well as temperatures, pressures and extent of oil pyrolysis for each of three desired system states and for the final depressurized state. Also, pyrolysis stoichiometry is set based on information given in the input file. The setting of stoichiometry is rather lengthy because parameters are set for each oil pseudocomponent in each of three RSTOIC modules. Also embedded in the block are a set of default values for all parameters read from the ASCII input file along with a brief description. Generally all default values are overwritten by data from the ASCII data file. The input from the ASCII file is done using a FORTRAN NAMELIST construct. The data in the ASCII file for a typical rin is described later.

The next block in the ".inp" file is also a FORTRAN BLOCK. This block, INIT, is meant to run as soon as the primary input stream has been generated by a MOXF module. This block sets the overall system density, which is invariant until depressurization, and is used by the DESIGN-SPEC's to compute system pressure. The next section of the file, from lines 803 to 824, sets up some control and reporting information. For the ASPEN PLUS model itself, English input units have been used since all the information on the crude oil is in English units. However, the computed results are to be reported primarily in SI units.

The next section, lines 825-973, define the property options and sets up the pseudocomponents used to represent the crude oil. The ASPEN PLUS FREEWATER option is used along with a so called API method for computing liquid volumes tailored for petroleum liquids. A number of possible property model sets are commented out, the preferred GRAYSON set is active. The SOLU-WATER=1 refers to the type of activity model chosen for water in the oil phase. This is the model describe in the body of the text. The list of components includes standard species and several others used to complete the description of the stoichiometry of the oil pyrolysis. The component HHC is a generic name intended to be used for a light hydrocarbon product of pyrolysis not included in the set list. This allows runs in which various species are used without effecting the coding in the model. The current version uses normal butane. If this species is changed, then its molecular weight needs to be set accordingly, see notes in lines 850-851. P-OIL is the assumed oil product of the pyrolysis and its properties are set using its assumed boiling point and gravity. Other oils similar to the pseudocomponents used in the crude representation are included in comment lines for reference. If the properties of POIL are changed, then the molecular weight, set in SETI line 544, should be changed as needed. The PROP-DATA paragraph beginning on line 870 is included so that the water solubility parameters for oil components can be modified from their ASPEN 
PLUS default values. Solubility of water in all components except the crude oil components are set to very small values. Those component names not included in the COMPONENTS list are for the pseudocomponents used to define the crude oil. For reference a number of types of solubility relations are included in comment lines. The active set is for the modified surfactant solubility set described in the report body. The final portion of this section, lines 917-973, defines the pseudocomponents used to represent the crude oil. This is done using ASPEN PLUS implemented routines to develop amounts and properties from crude oil cut information. This section must be modified if a different crude oil is used in the simulation. The final BLEND paragraph sets the crude oil composition. The comments document how the lighter ends were increased in order to modify the composition of the 11.5 API gravity crude oil to represent the 13.5 API gravity oil used in the experiments.

The next section, lines 974-1006, describes the four flowsheets used in the model. Notice a DUP module is used to feed the same stream to each of the first three flowsheet areas. These three areas perform essentially identical calculations but can have different reaction extents and temperatures. The pressures are set by DESIGNSPECS based on density as described above. The fourth area allows vapor to flash off setting the desired final pressure.

The next section simply defines default values for input streams. The flow rates are generally overwritten by data from the ASCII input file.

Starting on line 1022 is the block specification section where parameters for all process modules are defined.

The next section, lines 1137-1190, defines the design specifications used to compute the pressure in the autoclave based on a known overall system density. Three DESIGN-SPEC paragraphs are used, one each for flowsheets 1-3.

The final section; starting on line 1191, is a FORTRAN block used to collect selected computed information and print it in a summary table to the ASPEN PLUS report file. This table can be found in the ".rep" file by searching for the "=========" pattern.

As stated above, a given simulation is meant to get its primary input information not from the ".inp" file but rather from a ASCII input file. This file is read with the FORTRAN namelist feature. The namelist format has been slightly augmented by coding in the SETI block to allow comment only lines to be included. The comment lines must begin with "*". A sample input file is included after the ASPEN PLUS input file at the end of this appendix and its contents are briefly describe below. The input variables used can be linked to the ASPEN PLUS file by there names. Some additional comments on variable are present in the ".inp" file. 
The first data entry in the sample ASCII input file is on line 5 and sets the amounts of crude oil, water and nitrogen, in kilograms, loaded into the autoclave. Lines 1221 define the stoichiometry of the pyrolysis reaction. This same stoichiometry is applied to each of the crude oil pseudocomponents. The first two variables "wtfc" and "wtfo" are the weight fraction of reacted component which forms coke (taken as carbon in the model) and the oil product P-OIL. The remaining variables define all other products on a relative mole basis. In the input shown, they are all ratioed to methane.

Lines 25-31 define a measured dry-gas composition and are only included for convenience in looking at the output. They are not used in any of the model calculations. This same comment is true of the next input, the amount of coke in kilograms, in line 34.

Lines 39-44 define the extent of the pyrolysis reactions which are desired to occur in each flowsheet area. The variable "er' is the extent of reaction as a fraction of the reactant (i.e., each crude oil component) and is used as the reaction extent in flowsheet area 3. The variables "fer1" and "fer2" define the amount of reaction occurring in flowsheet area 1 and 2 respectively relative to "er". That is, the extent of reaction in flowsheet area 1 is the product of "er" and "fer1".

The temperatures desired for flowsheet areas is specified in degrees celsius in lines 49-52. With each temperature specification "tcn" where " $n$ " is 1,2 or 3 a corresponding pressure is entered. These pressures are for output only and are not used in the model calculations. The temperature for the fourth flowsheet area is assumed to be the same as that in the third, "tc3", the pressure is set in the ".inp' file to $0.1 \mathrm{MPa}$ in the fourth flow sheet area.

The following is the listing for the ASPEN PLUS ".inp" file.

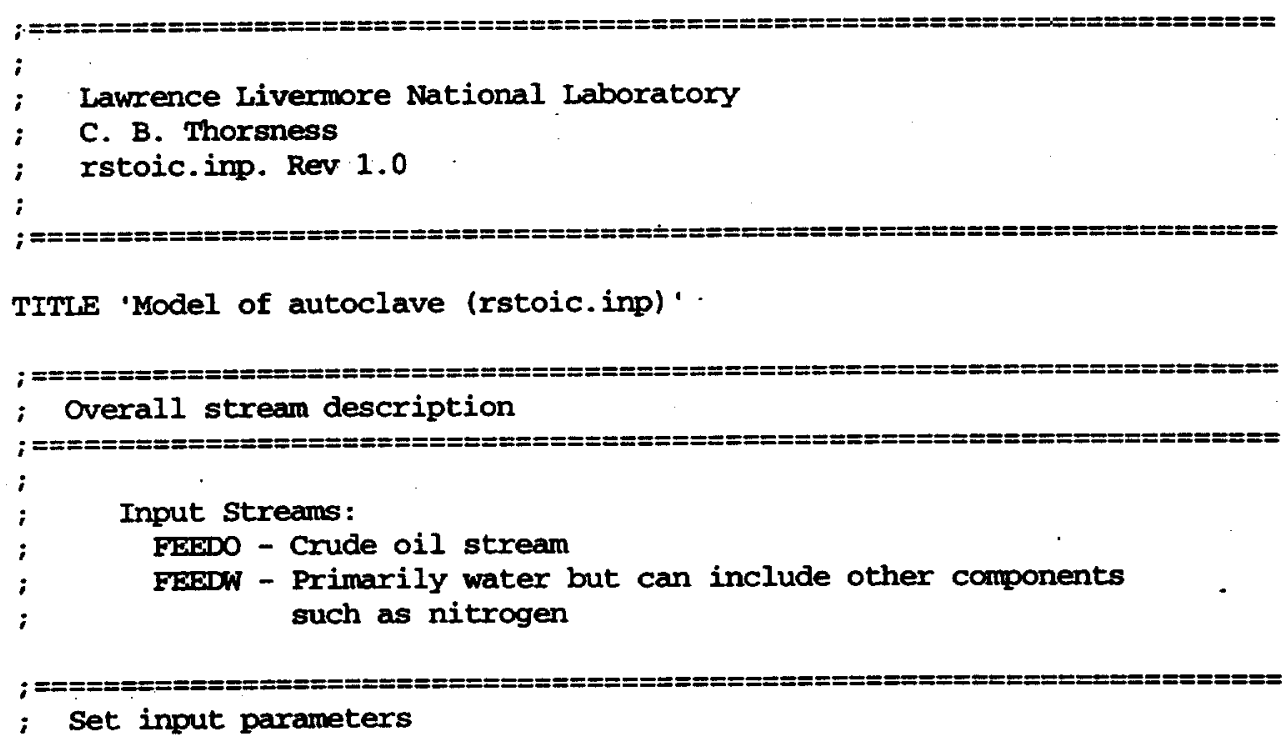




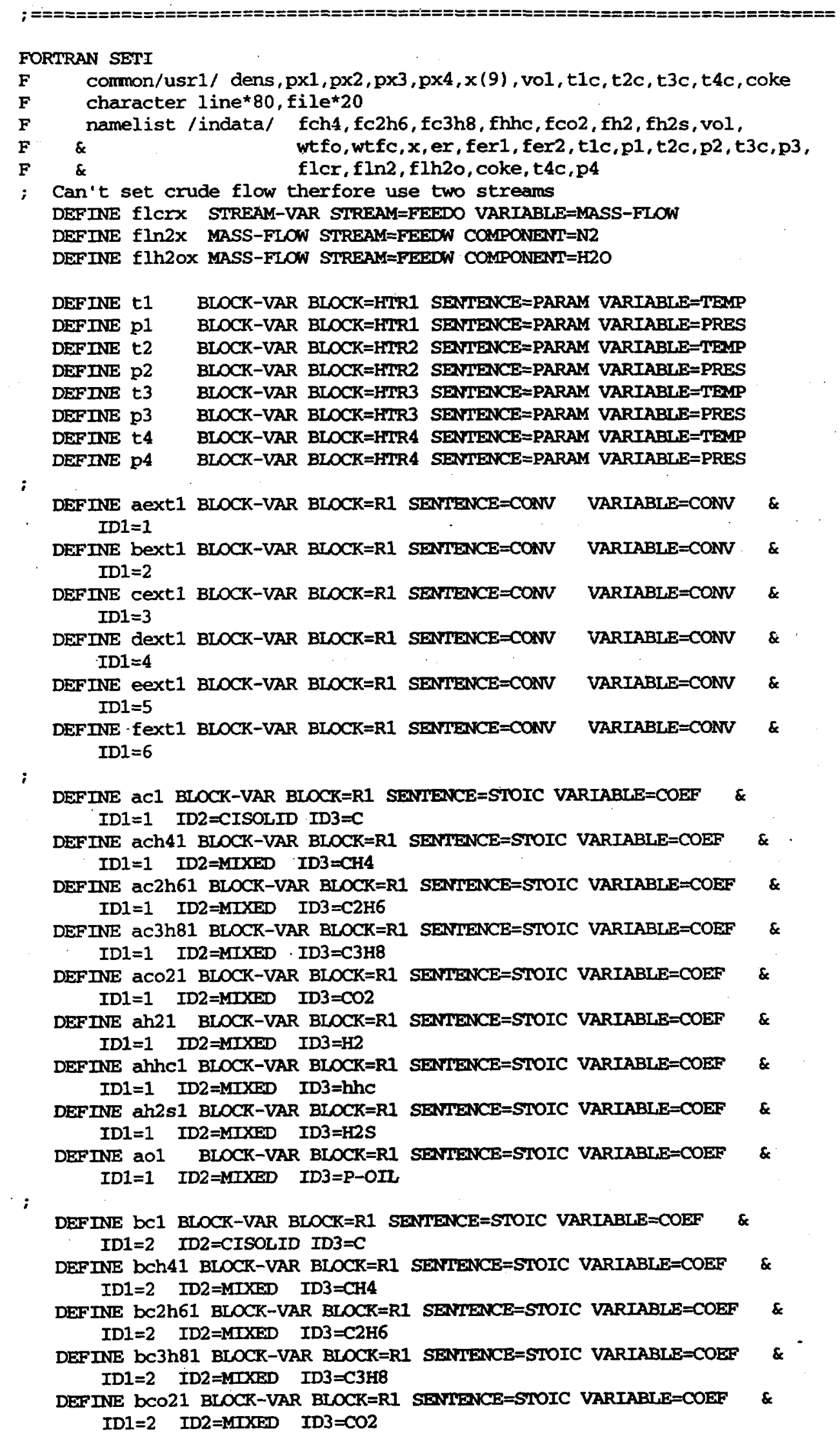


DEFTNE bh21 BLOCK-VAR BLOCK=R1 SENTENCE=STOIC VARIABLE=COEF \& ID1=2 ID2 =MTXED ID3=H2

DEFINE bhhC1 BLOCK-VAR BLOCK=R1 SENIENCE=STOIC VARIABLE=COEF \& ID1 $=2$ ID2 = MIXED ID3=hhC

DEFINE bh2 1 BLOCK-VAR BLOCK=R1 SENTENCE=STOIC VARIABLE=COEF \& ID1 $=2$ ID2=MIXED ID3=H2S

DEFINE bO1 BLOCK-VAR BLOCK=R1 SENTENCE=STOIC VARIABLE=COEF \& ID1=2 ID2=MIXED ID3=P-OIL

;

DEFINE CCI BLOCK-VAR BLOCK=R1 SENTENCE=STOIC VARIABLE=COEF \& ID1 $=3$ ID2 $=$ CISOLID ID3 $=C$

DEFINE CCh41 BLOCK-VAR BLOCK=R1 SENTENCE=STOIC VARIABLE=COEF \& ID1 $=3$ ID2 $=\mathrm{MDXED}$ ID3 $=\mathrm{CH} 4$

DEFINE CC2h61 BLOCK-VAR BLOCK=R1 SENTENCE=STOIC VARIABLE=COEF * $I D 1=3$ ID2 $=$ MIXED ID3 $=\mathrm{C} 2 \mathrm{H} 6$

DEF INE CC3h81 BLOCK-VAR BLOCK=R1 SENTENCE=STOIC VARIABLE=COEF \& $I D 1=3 \quad I D 2=M I X E D \quad I D 3=C 3 H 8$

DEFINE $C \mathrm{CO} 21$ BLOCK-VAR BLOCK=R1 SENTENCE=STOIC VARIABLE=COEF \& ID1 $=3$ ID2 $=\mathrm{MIXED}$ ID3 $=\mathrm{CO} 2$

DEFINE Ch21 BLOCK-VAR BLOCK=R1 SENTENCE=STOIC VARIABLE=COEF \& ID1 $=3$ ID2 = MIXXED ID3 $=\mathrm{H} 2$

DEFINE chhc1 BLOCK-VAR BLOCK=RI SENTENCE=STOIC VARTABLE=COEF \& ID1=3 ID2=MIXED ID3=hhc

DEFINE ch2s I BLOCK-VAR BLOCK=R1 SENIENCE=STOIC VARIABLE=COEF * \& $I D 1=3$ ID $2=\mathrm{MIXEND}$ ID $3=\mathrm{H} 2 \mathrm{~S}$

DEFINE CO1 BLOCK-VAR BLOCK=R1 SENTENCE=STOIC VARIABLE=COEF \& ID1=3 ID2=MIXED ID3=P-OIL

;

DEFINE dC1 BLOCK-VAR BLOCK=R1 SENTENCE=STOIC VARIABLE=COEF \& ID1 $=4$ ID2 $=$ CISOLID ID3 $=C$

DEFINE dCh41 BLOCK-VAR BLOCK=R1 SENIENCE=STOIC VARIABLE=COEF \& ID1 $=4$ ID2 $=$ MIXED ID3 $=\mathrm{CH} 4$

DEFINE dc2h61 BLOCK-VAR BLOCK=R1 SENIENCE=STOIC VARIABLE=COEF \& ID1 $=4 \quad I D 2=\mathrm{MIXED} \quad \mathrm{ID} 3=\mathrm{C} 2 \mathrm{H} 6$

DEFINE dC3h81 BLOCK-VAR BLOCK=R1 SENTENCE=STOIC VARIARLE=COEF \& ID1 $=4$ ID2 $=\mathrm{MIXED}$ ID3 $=\mathrm{C} 3 \mathrm{H} 8$

DEFINE dCO21 BLOCK-VAR BLOCK=R1 SENTENCE=STOIC VARTABLE=COEF \& $\mathrm{ID} 1=4$ ID2 $=\mathrm{MTXED}$ ID3 $=\mathrm{CO} 2$

DEFINE dh21 BLOCK-VAR BLOCK=R1 SENTENCE=STOIC VARIABLE=COEF \& ID1 $=4$ ID2 $=M I X E D$ ID3 $=\mathrm{H} 2$

DEFINE dhhCl BLOCK-VAR BLOCR=R1 SENIENCE=STOIC VARIABLE=COEF \& ID1=4 ID2 =MIXED ID3=hhC

DEFINE dh2s 1 BLOCK-VAR BLOCK=R1 SENTENCE=STOIC VARIABLE=COEF \& $I D 1=4 \quad I D 2=\mathrm{MIXED}$ ID $3=\mathrm{H} 2 \mathrm{~S}$

DEFINE do1 BLOCK-VAR BLOCK=R1 SENTENCE=STOIC VARIABLE=COEF \& ID1 $=4$ ID2 $=\mathrm{MIXED}$ ID3=P-OIL

DEFINE EC1 BLOCK-VAR BLOCK=R1 SENTENCE=STOIC VARIABLE=COEF \& ID1 $=5$ ID2 $=$ CISOLID ID3 $=C$

DEFINE ECh 41 BLOCK-VAR BLOCK=R1 SENTENCE=STOIC VARIABLE=COEF \& ID1 $=5$ ID2 $=$ MIXED $\cdot$ ID3 $=\mathrm{CH} 4$

DEFTNE eC2h61 BLOCK-VAR BLOCK=R1 SENTENCE=STOIC VARIABLE=COEF \& ID1 $=5$ ID2 $=$ MIXED ID3 $=\mathrm{C} 2 \mathrm{H} 6$

DEFINE ec3h81 BLOCK-VAR BLOCK=R1 SENTENCE=STOIC VARIABLE=COEF \& ID1 $=5$ ID2 $=$ MIXXD ID3 $=$ C $3 \mathrm{H} 8$

DEFINE ECO21 BLOCK-VAR BLOCK=R1 SENIENCE=STOIC VARIABLE=COEF \&C $\mathrm{ID} 1=5 \quad \mathrm{ID} 2=\mathrm{MIXED} \quad \mathrm{ID} 3=\mathrm{CO} 2$

DEFINE eh21 BLOCK-VAR BLOCK=R1 SENIENCE=STOIC VARIABLE=COEF \& ID $1=5$ ID2 $=$ MIXED ID3 $=\mathrm{H} 2$

DEFINE ehhc1 BLOCK-VAR BLOCK=R1 SENTENCE=STOIC VARIABLE=COEF * $I D 1=5 \quad I D 2=M I X E D \quad I D 3=h h c$

DEFINE eh2s1 BLOCK-VAR BLOCK=R1 SENTENCE=STOIC VARIABLE=COEF * ID1 $=5$ ID2 $=$ MTXEDD ID3=F2S

DEFINE eo1 BLOCK-VAR BLOCK=R1 SENTENCE=STOIC VARIABLE=COEF \& 


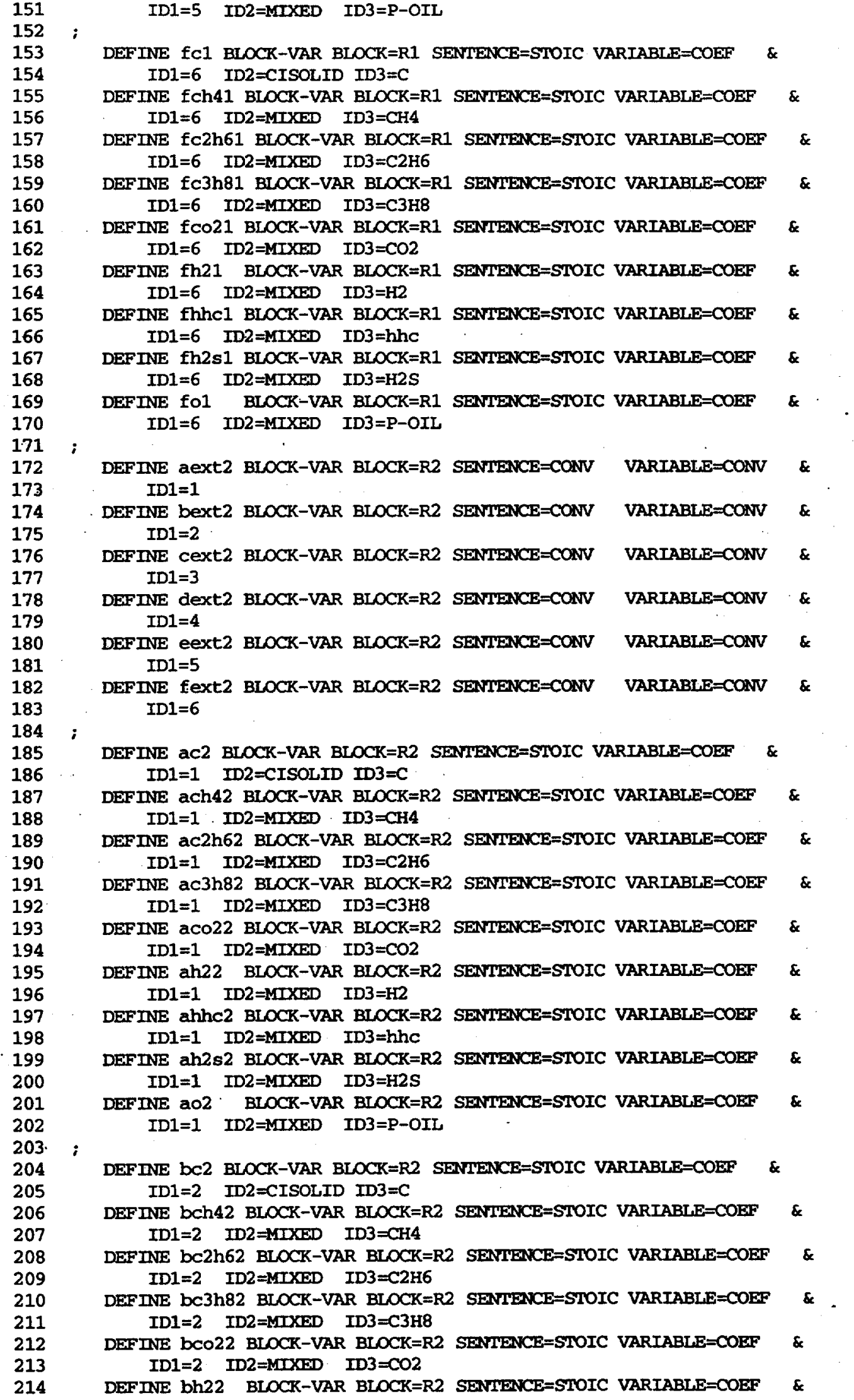

;

DEFINE IC1 BLOCK-VAR BLOCK=R1 SENTENCE=STOIC VARIABLE=COEF \& ID1 $=6$ ID2 $=$ CISOLID ID3 $=C$ DEFINE fCh41 BLOCK-VAR BLOCK=R1 SENTENCE=STOIC VARIABLE=COEF \& ID1 $=6$ ID2 $=\mathrm{MIXFD}$ ID3 $=\mathrm{CH} 4$

DEFINE fC2h61 BLOCK-VAR BLOCK=R1 SENTENCE=STOIC VARIABLE=COEF \& ID1=6 ID2 $=\mathrm{MIXED}$ ID3 $=\mathrm{C} 2 \mathrm{H} 6$

DEFINE fC3h81 BLOCK-VAR BLOCK=R1 SENTENCE=STOIC VARIABLE=COEF \& ID1 $=6$ ID2 =MIXED ID3=C3H8

DEFINE $f C O 21$ BLOCK-VAR BLOCK=R1 SENTENCE=STOIC VARIABLE=COEF \& ID1 $=6$ ID2 $=\mathrm{MIXED}$ ID3 $=\mathrm{CO} 2$

DEFINE fh21 BLOCK-VAR BLOCK=R1 SENTENCE=STOIC VARIABLE=COEF \& ID1 $=6$ ID2 $=$ MIXED ID3 $=\mathrm{H} 2$

DEFINE fhhC1 BLOCK-VAR BLOCK=RI SENTENCE=STOIC VARIABLE=COEF \& ID1 $=6$ ID2 $=$ MIXED ID $3=$ hhC

DEFTNE fh2s1 BLOCK-VAR BLOCK=R1 SENTEACE=STOIC VARTABLE=COEF \& ID1 $=6$ ID2=MIXEDD ID3=H2S

DEFINE fO1 BLOCK-VAR BLOCK=R1 SENTENCE=STOIC VARIABLE=COEF \& . $I D 1=6$ ID2=MIXED ID3=P-OIL

DEFINE aext2 BLOCK-VAR BLOCK=R2 SENTENCE=CONV VARIABLE=CONV \& $I D 1=1$

DEFINE bext2 BLOCK-VAR BLOCK=R2 SENTENCE=CONV VARIABLE=CONV \& $I D 1=2$

DEFINE cext2 BLOCK-VAR BLOCK=R2 SENTENCE=CONV $I D 1=3$

DEFINE dext2 BLOCK-VAR BLOCK=R2 SENTENCE=CONV $I D 1=4$

DEFINE eext2 BLOCK-VAR BIOCK=R2 SENTENCE=CONV $I D 1=5$

DEFINE fext2 BLOCK-VAR BLOCK=R2 SENTENCE=CONV VARIABLE=CONV \& $\mathrm{IDl}=6$

DEFINE AC2 BLOCK-VAR BLOCK=R2 SENIENCE=STOIC VARIABLE=COEF \& ID1=1 ID2=CISOLID ID3=C

DEF INE ach42 BLOCK-VAR BLOCK=R2 SENTENCE=STOIC VARIABLE=COEF \& $I D 1=1 \cdot I D 2=M I X E D D \cdot I D 3=C H 4$

DEFINE ac2h62 BLOCK-VAR BLOCK=R2 SENTENCE=STOIC VARIABLE=COEF \& ID1 $=1$ ID2=MIXED ID3 $=\mathrm{C} 2 \mathrm{H} 6$

DEFINE ac3h82 BLOCK-VAR BLOCK=R2 SENTENCE=STOIC VARIABLE=COEF \& ID1 $=1$ ID2=MIXED ID3 $=\mathrm{C} 3 \mathrm{HB}$

DEFINE aCO22 BLOCK-VAR BLOCK=R2 SENTENCE=STOIC VARIABLE=COEF \& ID1 $=1$ ID2 =MIXED ID3 $=\mathrm{CO} 2$

DEFINE ah22 BLOCK-VAR BLOCK=R2 SENTENCE=STOIC VARIABLE=COEF \& ID1 $=1$ ID2 $=$ MIXED ID3=H2

DEFINE ahhC2 BLOCK-VAR BLOCK=R2 SENTENCE=STOIC VARIABLE=COEF * ID1 $=1$ ID2 $=$ MIXED ID3=hhC

DEFINE ah2s2 BLOCK-VAR BLOCK=R2 SENTENCE=STOIC VARIABLE=COEF \& ID1 $=1$ ID2=MIXED ID3=H2S

DEFINE AO2 BLOCK-VAR BLOCK=R2 SENTENCE=STOIC VARIABLE=COEF \& ID1=1 ID2=MIXED ID3=P-OIL

DEFTNE bC2 BLOCK-VAR BLOCK=R2 SENTEACE=STOIC VARIABLE=COEF \& ID1 $=2$ ID2=CISOLID ID3=C

DEFINE bCh42 BLOCK-VAR BLOCK=R2 SENTENCE=STOIC VARIABLE=COEF \& ID1 $=2$ ID2 $=\mathrm{MIXED}$ ID3 $=\mathrm{CH} 4$

DEFINE bC2h62 BLOCK-VAR BLOCK=R2 SENTENCE=STOIC VARIABLE=COEF \& ID $1=2$ ID2 $=$ MIXED ID $3=C 2 \mathrm{H} 6$

DEFINE bC3h82 BLOCK-VAR BLOCK=R2 SENTENCE=STOIC VARIABLE=COEF \& . ID1 $=2$ ID2=MIXED ID3 $=$ C3H8

DEFINE bCO22 BLOCK-VAR BLOCK=R2 SENTENCE=STOIC VARIABLE=COEF \& $\mathrm{ID} 1=2 \quad \mathrm{ID} 2=\mathrm{MIXED} \quad \mathrm{ID} 3=\mathrm{CO} 2$

DEF INE bh22 BLOCK-VAR BLOCK=R2 SENTENCE=STOIC VARIABLE=COEF \& 


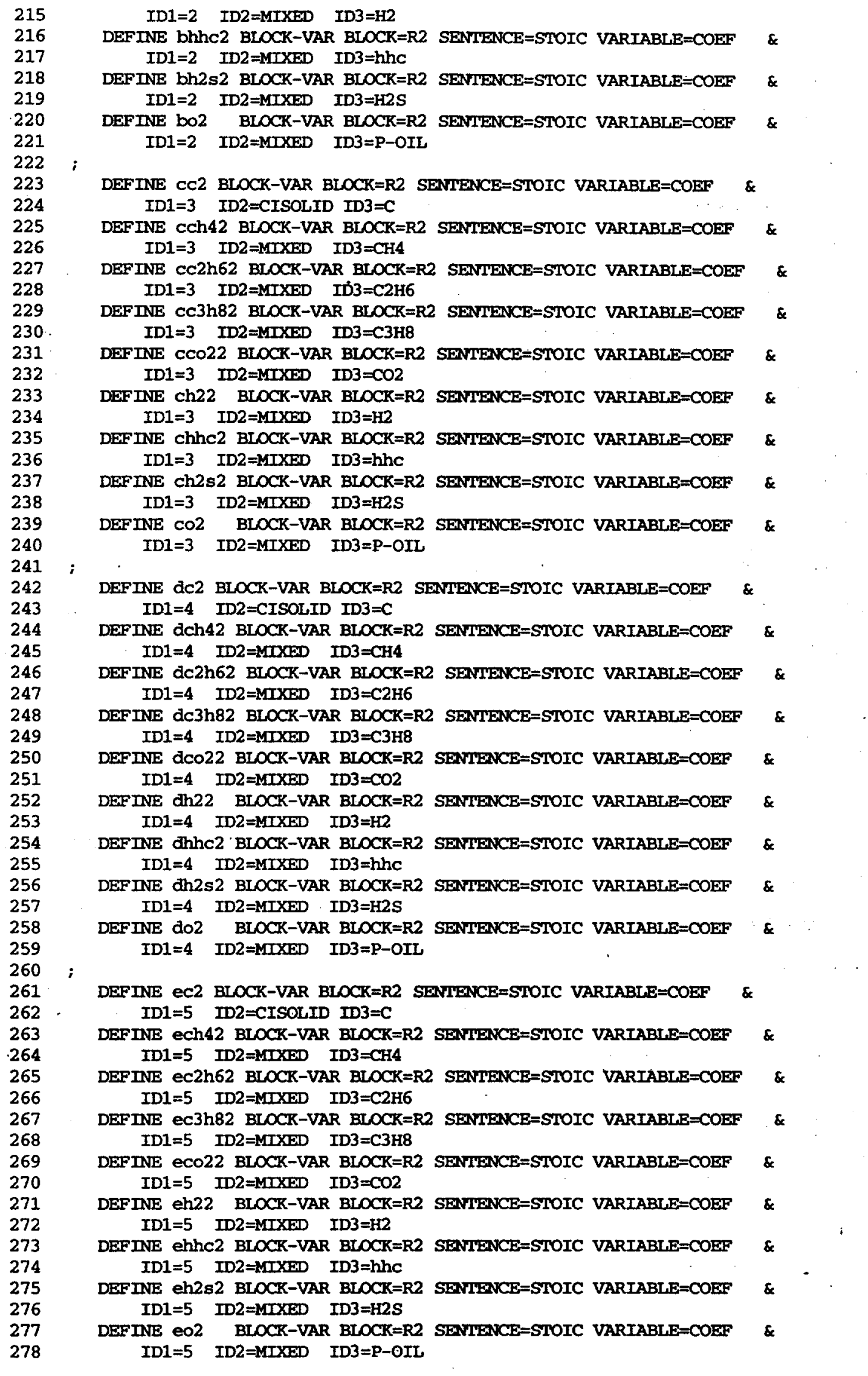




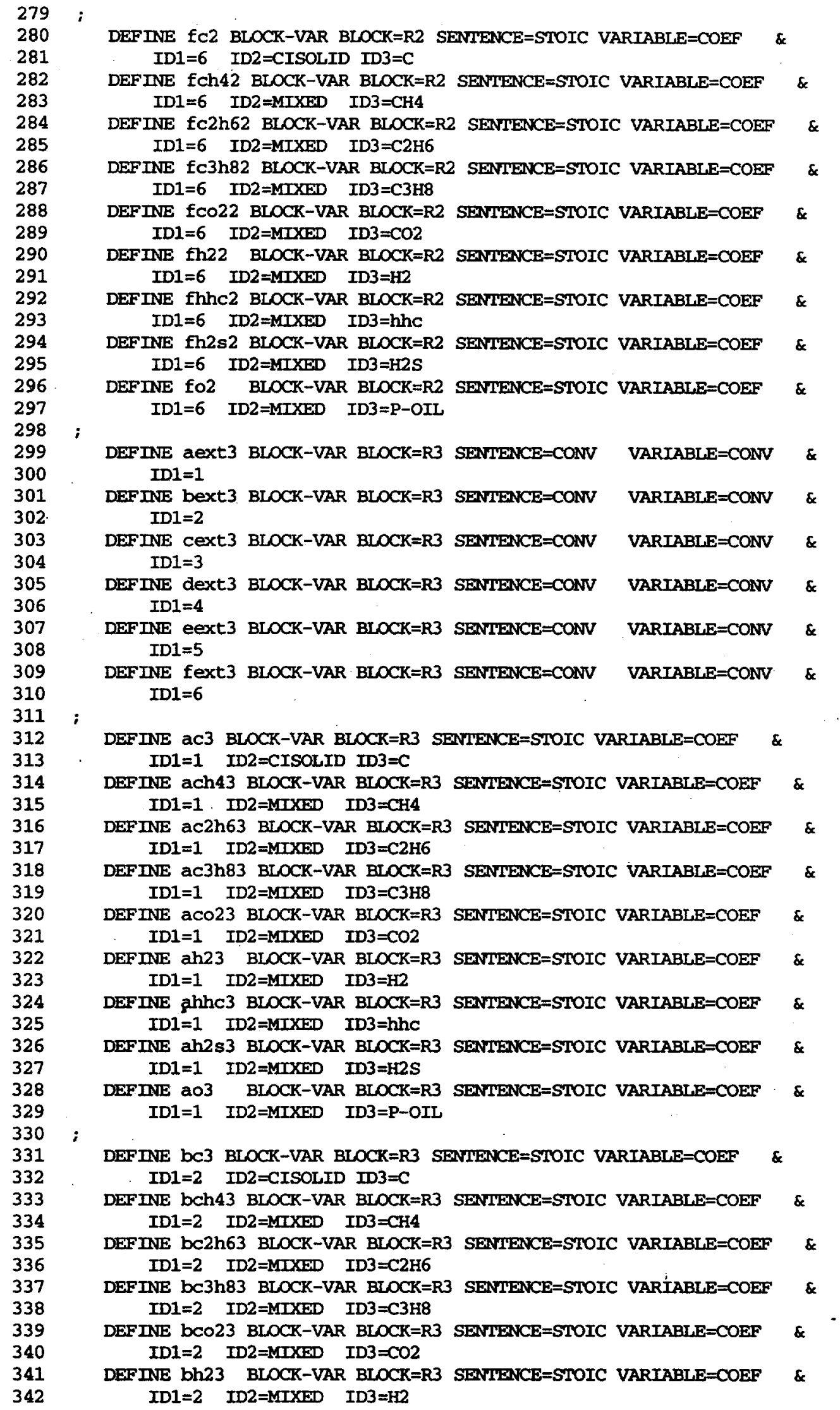


DEFINE bhhC 3 BLOCK-VAR BLOCK=R3 SENTENCE=STOIC VARIABLE=COEF ID1 $=2$ ID2 = MIXED ID3 $=$ hhc

DEFINE bh2s3 BLOCK-VAR BLOCK=R3 SENTENCE=STOIC VARIABLE=COEF \& ID1 $=2$ ID2 $=$ MIXED ID $3=\mathrm{H} 2 \mathrm{~S}$

DEFINE bO3 BLOCK-VAR BLOCK=R3 SENTENCE=STOIC VARIABLE=COEF \& ID1=2 ID2=MIXED ID3=P-OIL

DEF TNE CC3 BLOCK-VAR BLOCK=R3 SENTENCE=STOIC VARIABLE=COEF \& ID1 $=3$ ID2 $=$ CISOLID ID $3=C$

DEFINE CCh43 BLOCK-VAR BLOCK=R3 SENTENCE=STOIC VARIABLE=COEF \& $I D 1=3 \quad$ ID2 $=$ MIXED ID3 $=\mathrm{CH} 4$

DEFINE CC2h63 BLOCK-VAR BLOCK=R3 SENIENCE=STOIC VARIABLE=COEF \& ID1 $=3$ ID2 $=$ MIXED ID $3=\mathrm{C} 2 \mathrm{H} 6$

DEFINE CC3h83 BLOCK-VAR BLOCK=R3 SENTENCE=STOIC VARIABLE=COEF \& ID1 $=3$ ID2 $=$ MIXED ID3 $=\mathrm{C} 3 \mathrm{H} 8$

DEFINE CCO23 BLOCK-VAR BLOCK=R3 SENTENCE=STOIC VARIABLE=COEF \& ID1=3 ID2 = MIXXDD ID3 $=\mathrm{CO} 2$

DEFINE ch23 BLOCK-VAR BLOCK=R3 SENTENCE=STOIC VARIABLE=COEF \& ID1 $=3$ ID2 $=\mathrm{MIXED}$ ID3 $=\mathrm{H} 2$

DEFINE chhc3 BLOCK-VAR BLOCK=R3 SENTENCE=STOIC VARIABLE=COEF \& $I D 1=3 \quad I D 2=M I X E D \quad I D 3=h h c$

DEFINE ch2s3. BLOCK-VAR BLOCK=R3 SENTENCE=STOIC VARIABLE=COEF \& ID1 $=3$ ID2=MIXED ID3 $=\mathrm{H} 2 \mathrm{~S}$

DEFINE CO3 BLOCK-VAR BLOCK=R3 SEANTENCE=STOIC VARIABLE=COEF \& ID1=3 ID2=MIXED ID3=P-OIL

DEFINE dC3 BLOCK-VAR BLOCK=R3 SENTEANE=STOIC VARIABLE=COEF * \& ID1 $=4$ ID2 $=$ CISOLID ID $3=\mathrm{C}$

DEFINE dCh 43 BLOCK-VAR BLOCK=R3 SENTENCE=STOIC VARIABLE=COEF \& $I D 1=4 \quad I D 2=M I X E D$ ID3 $=C H 4$

DEFINE dC2h63 BLOCK-VAR BLOCK=R3 SENTENCE=STOIC VARIABLE=COEF \& ID1=4 ID2=MIXED ID3=C2H6

DEFINE dC3h83 BLOCK-VAR BLOCK=R3 SENTENCE=STOIC VARIABLE=COEF \& ID $1=4$ ID2 $=$ MIXED ID $3=\mathrm{C} 3 \mathrm{H} 8$

DEFINE dCO23 BLOCK-VAR BLOCK=R3 SEMTEACE=STOIC VARIABLE=COEF \& ID1 $=4$ ID2 $=$ MIXED ID3 $=\mathrm{CO} 2$

DEFINE dh23 BLOCK-VAR BLOCK=R3 SENTENCE=STOIC VARIABLE=COEF \& ID $1=4$ ID2 $=$ MIXED ID3 $=\mathrm{H} 2$

DEFINE dhhc 3 BLOCK-VAR BLOCK=R3 SENIENCE=STOIC VARIABLE=COEF \& ID $1=4$ ID2 =MIXED ID3=hhC

DEFINE dh2s 3 BLOCK-VAR BLOCK=R3 SENTENCE=STOIC VARIABLE=COEF \& ID1 $=4 \quad$ ID2 =MIXED ID3=H2S

DEFINE dO3 BLOCK-VAR BLOCK=R3 SENTENCE=STOIC VARIABLE=COEF \& ID1=4 ID2=MIXED ID3=P-OIL

DEFINE EC3 BLOCK-VAR BLOCK=R3 SENTERNCE=STOIC VARIABLE=COEF \& ID1=5 ID2 =CISOLID ID3 $=C$

DEFINE ech43 BLOCK-VAR BLOCK=R3 SENTENCE=STOIC VARIABLE=COEF ID1 $=5$ ID2 $=\mathrm{MIXED}$ ID $3=\mathrm{CH} 4$

DEFINE EC2h63 BLOCK-VAR BLOCK=R3 SENTENCE=STOIC VARIABLE=COEF \& ID1 $=5$ ID2 $=\mathrm{MIXED}$ ID3 $=\mathrm{C} 2 \mathrm{H} 6$

DEFINE ec3h83 BLOCK-VAR BLOCK=R3 SENTEANCE=STOIC VARIABLE=COEF \& ID1 $=5$ ID2 $=$ MIXED $I D 3=C 3 \mathrm{H} 8$

DEFINE ECO23 BLOCK-VAR BLOCK=R3 SENTENCE=STOIC VARIABLE=COEF \& ID1 $=5$ ID2 $=\mathrm{MIXED}$ ID3 $=\mathrm{CO} 2$

DEFINE eh23 BLOCK-VAR BLOCK=R3 SENTENCE=STOIC VARIABLE=COEF \& ID1 $=5$ ID2 $=\mathrm{MIXED} \quad$ ID3 $=\mathrm{H} 2$

DEF INE ehhc3 BLOCK-VAR BLOCK=R3 SENTENCE=STOIC VARIABLE=COEF \& ID1 $=5$ ID2 $=$ MIXED ID3 =hhc

DEFINE eh2s3 BLOCK-VAR BLOCK=R3 SENIENCE=STOIC VARIABLE=COEF $\mathrm{ID} 1=5$ ID2 $=\mathrm{MIXED}$ ID $3=\mathrm{H} 2 \mathrm{~S}$

DEFINE EO3 BLOCK-VAR BLOCK=R3 SENTENCE=STOIC VARIABLE=COEF \& ID1=5 ID2=MIXED ID3 =P-OIL 


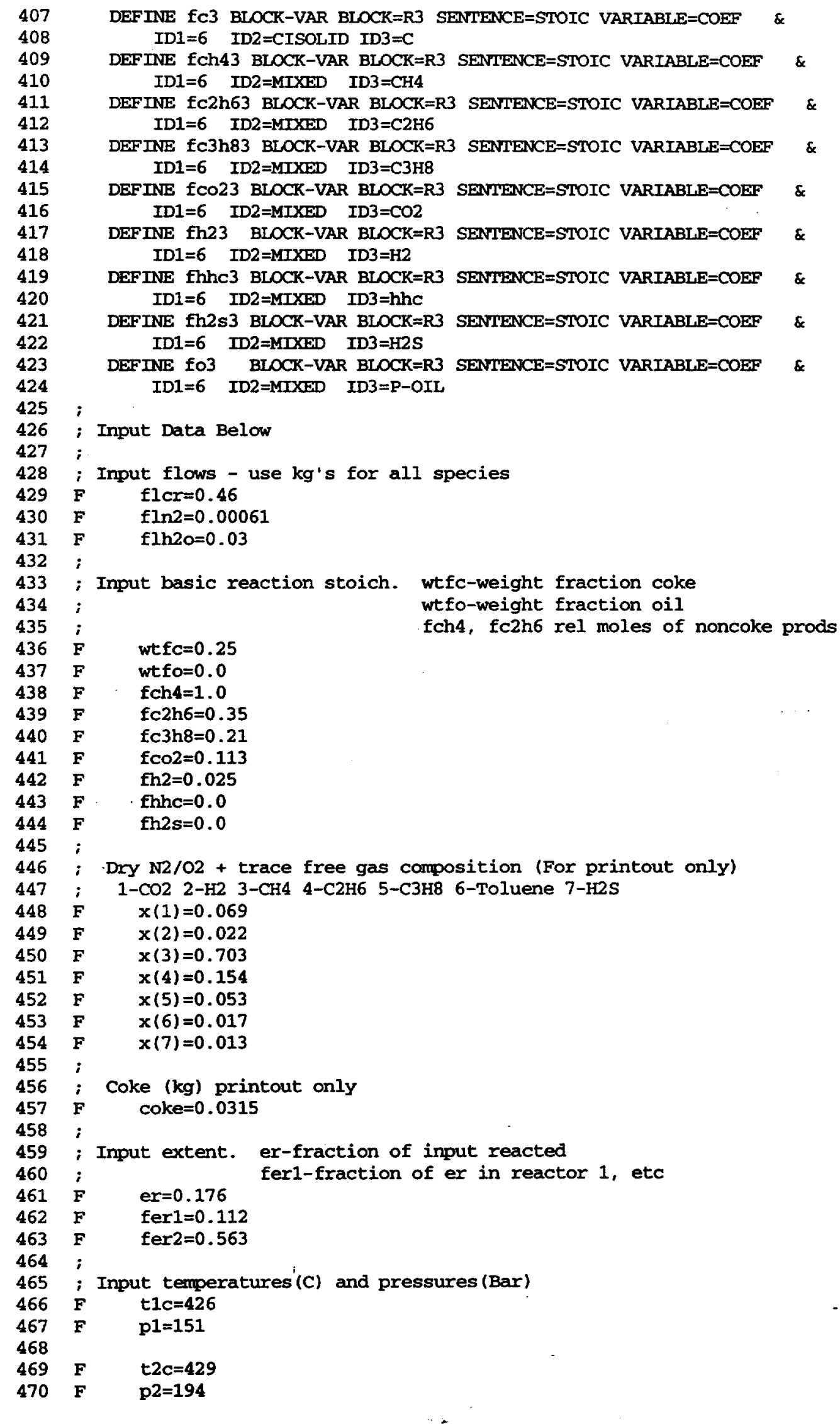




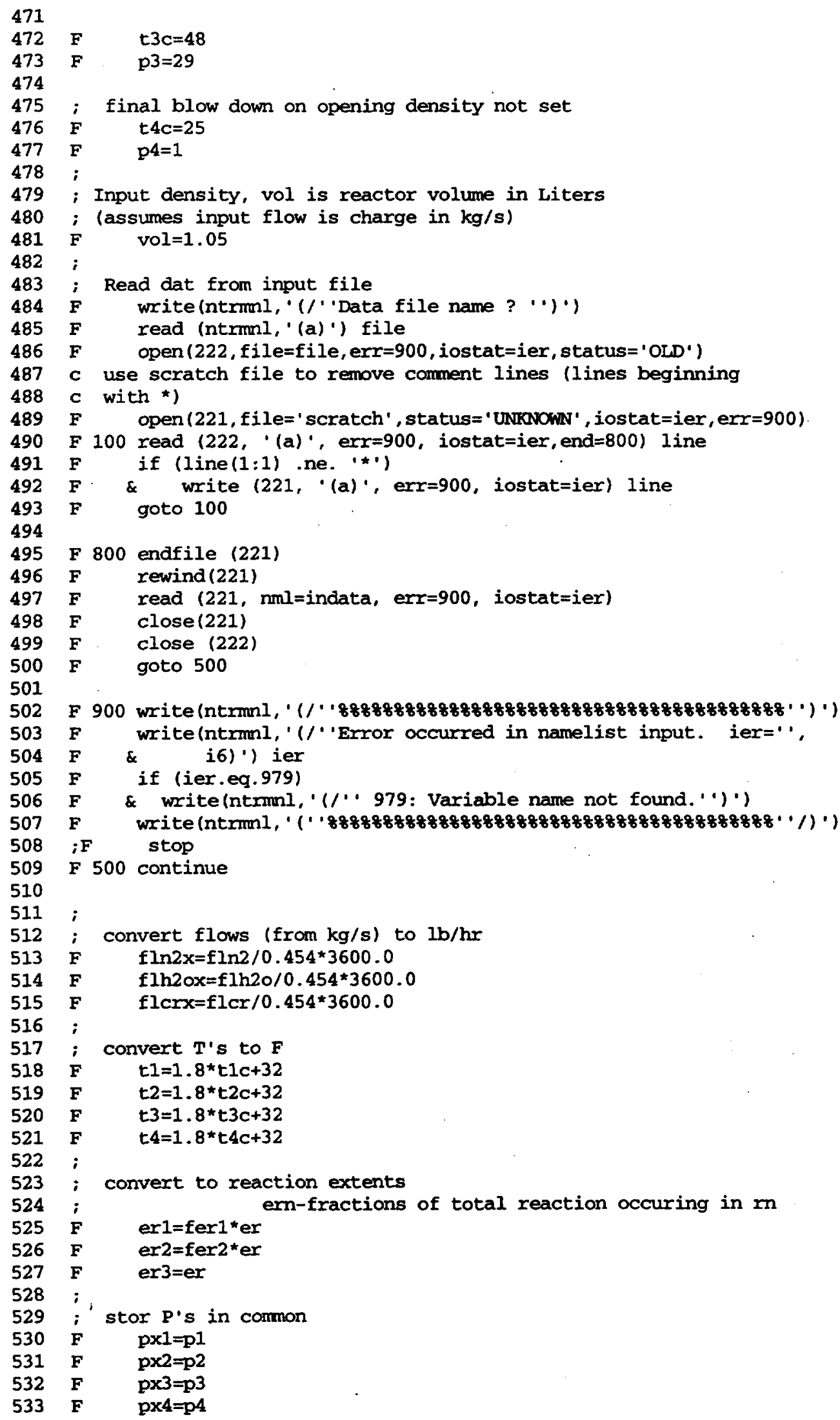




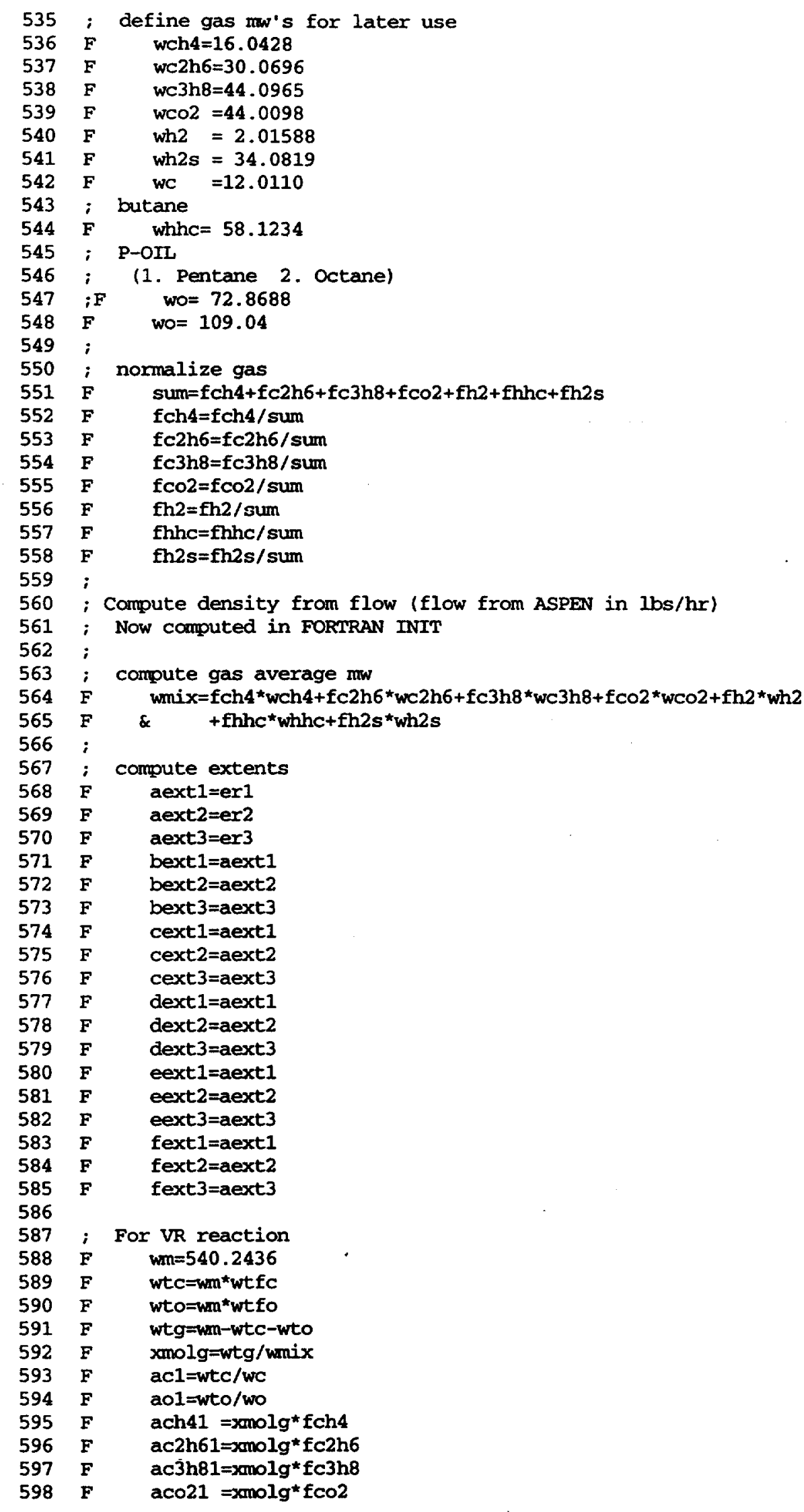




\begin{tabular}{|c|c|c|}
\hline 599 & $\mathbf{F}$ & ah21 $=$ xmolg* fh2 \\
\hline 600 & $\mathbf{F}$ & ahhcl $=x m o l g *$ fhhc \\
\hline 601 & $\mathbf{F}$ & ah2s1 =xmolg* fh2s \\
\hline 602 & $\mathbf{F}$ & $\mathrm{ac2}=\mathrm{ac1}$ \\
\hline 603 & $\mathbf{F}$ & $a 02=a 01$ \\
\hline 604 & $\mathbf{F}$ & $\operatorname{ach} 42=\operatorname{ach} 41$ \\
\hline 605 & $F$ & $\operatorname{ac} 2 \mathrm{~h} 62=\mathrm{ac} 2 \mathrm{~h} 61$ \\
\hline 606 & $\mathbf{F}$ & ac3h82=ac3h81 \\
\hline 607 & $\mathbf{F}$ & $a c o 22=a c o 21$ \\
\hline 608 & $\mathbf{F}$ & $a h 22=a h 21$ \\
\hline 609 & $\mathbf{F}$ & ahhc2 $=$ ahhc1 \\
\hline 610 & $\mathbf{F}$ & ah2s2 $=a h 2 s 1$ \\
\hline 611 & $\mathbf{F}$ & $\mathrm{ac} 3=\mathrm{ac} 1$ \\
\hline 612 & $\mathbf{F}$ & $a 03=a 01$ \\
\hline 613 & $\mathbf{F}$ & $\operatorname{ach} 43=\operatorname{ach} 41$ \\
\hline 614 & $\mathbf{F}$ & $\operatorname{ac} 2 \mathrm{~h} 63=\operatorname{ac} 2 \mathrm{~h} 61$ \\
\hline 615 & $F$ & ac3h83=ac3h81 \\
\hline 616 & $\mathbf{F}$ & $a c 023=a c 021$ \\
\hline 617 & $\mathbf{F}$ & $a h 23=a h 21$ \\
\hline 618 & $\mathbf{F}$ & ahhc3=ahhc1 \\
\hline 619 & $\mathbf{F}$ & $\operatorname{ah} 2 s 3=\operatorname{ah} 2 s 1$ \\
\hline 620 & ; & \\
\hline 621 & ; & For HVGO reaction \\
\hline 622 & $F$ & $w_{2 n}=410.7407$ \\
\hline 623 & $F$ & $w t c=w m^{*} w t f c$ \\
\hline 624 & $F$ & $w t o=w m^{*} w t$ fo \\
\hline 625 & $F$ & $w t g=w n-w t c-w t o$ \\
\hline 626 & $F$ & xmolg=wtg/wmix \\
\hline 627 & $\boldsymbol{F}$ & $b c 1=w t c / w c$ \\
\hline 628 & $F$ & bo1=wto/wo \\
\hline 629 & $F$ & bch41 =xmolg* fch 4 \\
\hline 630 & $\mathbf{F}$ & $\mathrm{bc} 2 \mathrm{~h} 61=\mathrm{xmolg}{ }^{*} \mathrm{fc} 2 \mathrm{~h} 6$ \\
\hline 631 & $\mathbf{F}$ & $b c 3 h 81=x \operatorname{molg} f^{*} f(h)$ \\
\hline 632 & F & $b c 021=x m o l g * f c o 2$ \\
\hline 633 & $\mathbf{F}$ & bh21 =xmolg* fh2 \\
\hline 634 & $\mathbf{F}$ & bhhc1=xmolg* fhhc \\
\hline 635 & $\mathbf{F}$ & bh2s1 =xmolg*fh2s \\
\hline 636 & $\mathbf{F}$ & $\mathrm{bc2}=\mathrm{bcc}$ \\
\hline 637 & $\mathrm{~F}$ & $\mathrm{bo} 2=\mathrm{bol}$ \\
\hline 638 & $\mathbf{F}$ & bch42 =bch41 \\
\hline 639 & F & $\mathrm{bc} 2 \mathrm{~h} 62=\mathrm{bc} 2 \mathrm{~h} 61$ \\
\hline 640 & $\mathbf{F}$ & bc3h82=bc3h81 \\
\hline 641 & $\mathbf{F}$ & $\mathrm{bco} 22=\mathrm{bco} 21$ \\
\hline 642 & $\mathbf{F}$ & $\mathrm{bh} 22=\mathrm{bh} 21$ \\
\hline 643 & $\mathbf{F}$ & bhhc2=bhhc1 \\
\hline 644 & $\mathbf{F}$ & bh2s $2=b h 2 s 1$ \\
\hline 645 & $\mathbf{F}$ & $b c 3=b c 1$ \\
\hline 646 & $\mathbf{F}$ & $\mathrm{bo} 3=\mathrm{bo} 1$ \\
\hline 647 & $\mathbf{F}$ & bch $43=$ =bch 41 \\
\hline 648 & $\mathbf{F}$ & $\mathrm{bc} 2 \mathrm{~h} 63=\mathrm{bc} 2 \mathrm{~h} 61$ \\
\hline 649 & $F$ & bc3h83=bc3h81 \\
\hline 650 & $F$ & $\mathrm{bco} 23=\mathrm{bco} 21$ \\
\hline 651 & $\mathbf{F}$ & $\mathrm{bh} 23=\mathrm{bh} 21$ \\
\hline 652 & $\mathbf{F}$ & bhhe3=bhhc1 \\
\hline 653 & $\mathbf{F}$ & $\mathrm{bh} 2 \mathrm{~s} 3=\mathrm{bh} 2 \mathrm{~s} 1$ \\
\hline 654 & $i$ & \\
\hline 655 & $i$ & For LVGO reaction \\
\hline 656 & $\mathbf{F}$ & $w_{1 n}=306.6466$ \\
\hline 657 & $\mathbf{F}$ & $w t c=w m^{\star} w t f c$ \\
\hline 658 & $\mathbf{F}$ & wto $=w m^{*}$ wt fo \\
\hline 659 & $\mathbf{F}$ & $w t g=w m-w t c-w t o$ \\
\hline 660 & $\boldsymbol{F}$ & xmolg=wtg/wmix \\
\hline 661 & $\mathbf{F}$ & $c c 1=w t c / w c$ \\
\hline 662 & $\mathbf{F}$ & $\operatorname{col}=w t o / w o$ \\
\hline
\end{tabular}




\begin{tabular}{|c|c|c|}
\hline 663 & $\mathbf{F}$ & $\operatorname{cch} 41=x \ln 1 g^{\star}$ fch 4 \\
\hline 664 & $\mathbf{F}$ & $\operatorname{cc} 2 \mathrm{~h} 61=x \mathrm{molg}$ * $\mathrm{fc} 2 \mathrm{~h} 6$ \\
\hline 665 & $\mathbf{F}$ & $\operatorname{cc} 3 h 81=x$ molg $*$ fc3h8 \\
\hline 666 & $\mathrm{~F}$ & $\operatorname{cco} 21=x m o l g * f c o 2$ \\
\hline 667 & $F$ & ch21 =xmolg* th2 \\
\hline 668 & $\mathbf{F}$ & chhel=xmolg* fhhc \\
\hline 669 & $\mathbf{F}$ & $\operatorname{ch} 2 s 1=x \operatorname{molg}{ }^{\star}$ th $2 \mathrm{~s}$ \\
\hline 670 & F & $\operatorname{cc} 2=\operatorname{cc} 1$ \\
\hline 671 & $\mathbf{F}$ & $\operatorname{co} 2=\operatorname{co} 1$ \\
\hline 672 & $\mathbf{F}$ & $\operatorname{cch} 42=\operatorname{cch} 41$ \\
\hline 673 & $\mathbf{F}$ & $\operatorname{cc} 2 \mathrm{~h} 62=\operatorname{cc} 2 \mathrm{~h} 61$ \\
\hline 674 & $\mathrm{~F}$ & $\operatorname{cc} 3 h 82=\operatorname{cc} 3 h 81$ \\
\hline 675 & $\mathbf{F}$ & $\operatorname{cco} 22=\operatorname{cco} 21$ \\
\hline 676 & $\mathbf{E}$ & $\operatorname{ch} 22=\operatorname{ch} 21$ \\
\hline 677 & $\mathbf{F}$ & chhc2=chhc1 \\
\hline 678 & $\mathbf{F}$ & $\operatorname{ch} 2 s 2=\operatorname{ch} 2 s 1$ \\
\hline 679 & $\mathbf{F}$ & $\operatorname{cc} 3=\operatorname{cc} 1$ \\
\hline 680 & $\mathbf{F}$ & $\operatorname{co} 3=\operatorname{col} 1$ \\
\hline 681 & $\mathbf{F}$ & $\operatorname{cch} 43=\operatorname{cch} 41$ \\
\hline 682 & $\mathbf{F}$ & $\operatorname{cc} 2 \mathrm{~h} 63=\mathrm{cc} 2 \mathrm{~h} 61$ \\
\hline 683 & $\mathbf{F}$ & $\operatorname{cc} 3 h 83=\operatorname{cc} 3 h 81$ \\
\hline 684 & $\mathbf{F}$ & $\operatorname{cco} 23=\operatorname{cco} 21$ \\
\hline 685 & $\mathbf{F}$ & $\operatorname{ch} 23=\operatorname{ch} 21$ \\
\hline 686 & $\mathbf{F}$ & chhe $3=$ chhe 1 \\
\hline 687 & $\mathbf{F}$ & $\operatorname{ch} 2 s 3=\operatorname{ch} 2 s 1$ \\
\hline 688 & ; & \\
\hline 689 & ; & For AGO reaction \\
\hline 690 & $\mathbf{F}$ & $w m=228.1870$ \\
\hline 691 & $F$ & $w_{t c}=w^{*}{ }^{*} w_{f} c$ \\
\hline 692 & $\mathbf{F}$ & $w t o=w^{\star} w t$ fo \\
\hline 693 & $\mathbf{F}$ & wtg=wn-wtc-wto \\
\hline 694 & $\mathbf{F}$ & xmolg=wtg/wmix \\
\hline 695 & $\mathbf{F}$ & $\mathrm{dcl}=\mathrm{wtc} / \mathrm{wc}$ \\
\hline 696 & $\mathbf{F}$ & dol=wto/wo \\
\hline 697 & $\mathbf{F}$ & dch41 =xmolg*fch 4 \\
\hline 698 & $\mathbf{F}$ & $\mathrm{dc} 2 \mathrm{~h} 61=\mathrm{xmolg} \mathrm{fc}^{2} \mathrm{~h} 6$ \\
\hline 699 & $\mathbf{F}$ & de3h81=xmolg*fc3h8 \\
\hline 700 & $\mathbf{F}$ & $\mathrm{dco} 21=\mathrm{xmnolg}^{\star} \mathrm{fco} 2$ \\
\hline 701 & $\mathbf{F}$ & dh21 =xmolg*fh2 \\
\hline 702 & $\mathbf{F}$ & dhhcl=xmolg* fhhc \\
\hline 703 & $\mathbf{F}$ & dh2s $1=x m o l g *$ fh $2 s$ \\
\hline 704 & $\mathbf{F}$ & $\mathrm{dc} 2=\mathrm{dc} 1$ \\
\hline 705 & $\mathbf{F}$ & do2 $=$ do 1 \\
\hline 706 & $\mathbf{F}$ & $\operatorname{dch} 42=\operatorname{deh} 41$ \\
\hline 707 & $\mathbf{F}$ & $\mathrm{dc} 2 \mathrm{~h} 62=\mathrm{dc} 2 \mathrm{~h} 61$ \\
\hline 708 & $\mathbf{F}$ & dc $3 h 82=d c 3 h 81$ \\
\hline 709 & $\mathbf{F}$ & $\mathrm{dco} 22=\mathrm{dco} 21$ \\
\hline 710 & $\mathbf{F}$ & $\operatorname{dh} 22=\operatorname{dh} 21$ \\
\hline 711 & $\mathbf{F}$ & dhhe2 $=$ dhhe1 \\
\hline 712 & $\mathbf{F}$ & $\operatorname{dh} 2 \mathrm{~s} 2=\mathrm{dh} 2 \mathrm{~s} 1$ \\
\hline 713 & $\mathbf{F}$ & $d c 3=d c 1$ \\
\hline 714 & $\mathbf{F}$ & do $3=d o 1$ \\
\hline 715 & $\mathbf{F}$ & $\operatorname{dch} 43=\operatorname{dch} 41$ \\
\hline 716 & $\mathrm{~F}$ & dc2h63=dc2h61 \\
\hline 717 & $\mathrm{~F}$ & $\mathrm{dc} 3 \mathrm{~h} 83=\mathrm{dc} 3 \mathrm{~h} 81$ \\
\hline 718 & $F$ & $\mathrm{dco} 23=\mathrm{dco} 21$ \\
\hline 719 & F & dh23 $=$ dh21 \\
\hline 720 & $\mathbf{F}$ & dhhe3=dhhc1 \\
\hline 721 & $\mathbf{F}$ & $\operatorname{dh} 2 \mathrm{~s} 3=\mathrm{dh} 2 \mathrm{~s} 1$ \\
\hline 722 & ; & \\
\hline 723 & ; & For KERO reaction \\
\hline 724 & $\mathbf{F}$ & $\mathrm{wm}=178.2905$ \\
\hline 725 & $\mathbf{F}$ & $w t c=w m^{*} w t f c$ \\
\hline 726 & $\mathbf{F}$ & $w t o=w m^{\star} w t$ fo \\
\hline
\end{tabular}




\begin{tabular}{|c|c|c|}
\hline 727 & $\mathbf{F}$ & $w t g=w n-w t c-w t o$ \\
\hline 728 & $\mathbf{F}$ & xmolg=wtg/umix \\
\hline 729 & $\mathbf{F}$ & ec1=wtc/wc \\
\hline 730 & $\mathbf{F}$ & eo1=wto/wo \\
\hline 731 & $\mathbf{F}$ & ech41 =xmolg* fch4 \\
\hline 732 & $\mathbf{F}$ & $\operatorname{ec} 2 \mathrm{~h} 61=x \mathrm{molg} \mathrm{g}^{\star} \mathrm{fc} 2 \mathrm{~h} 6$ \\
\hline 733 & $\mathbf{F}$ & ec3h81=xmolg* fc3h8 \\
\hline 734 & $\mathbf{F}$ & $\mathrm{eco} 21=\mathrm{xmolg} \mathrm{fco} 2$ \\
\hline 735 & $\mathbf{F}$ & eh21 =xmolg*fh2 \\
\hline 736 & $\mathbf{F}$ & ehhcl=xImolg* fhhc \\
\hline 737 & $\mathbf{F}$ & eh2s1 =xmolg*fh2s \\
\hline 738 & $F$ & $e c 2=e c 1$ \\
\hline 739 & $F$ & eo2 $2=e 01$ \\
\hline 740 & $\mathbf{F}$ & $\operatorname{ech} 42=\operatorname{ech} 41$ \\
\hline 741 & $F$ & ec $2 \mathrm{~h} 62=\mathrm{ec} 2 \mathrm{~h} 61$ \\
\hline 742 & $F$ & ec $3 h 82=e c 3 h 81$ \\
\hline 743 & $\mathbf{F}$ & $e c 022=e c 021$ \\
\hline 744 & $\mathbf{F}$ & eh22 =eh21 \\
\hline 745 & $\mathbf{F}$ & ehhc2=ehhc1 \\
\hline 746 & $\boldsymbol{F}$ & eh2s $2=e h 2 s 1$ \\
\hline 747 & $\mathbf{F}$ & ec3=ec1 \\
\hline 748 & F & eo $3=e o 1$ \\
\hline 749 & $\mathbf{F}$ & ech $43=\operatorname{ech} 41$ \\
\hline 750 & $\mathbf{F}$ & ec $2 \mathrm{~h} 63=\mathrm{ec} 2 \mathrm{~h} 61$ \\
\hline 751 & $\mathbf{F}$ & ec $3 h 83=e c 3 h 81$ \\
\hline 752 & $\mathbf{E}$ & eco23 =eco21 \\
\hline 753 & $\mathbf{F}$ & eh23 =eh21 \\
\hline 754 & $\boldsymbol{F}$ & ehhc3=ehhc1 \\
\hline 755 & $\mathbf{F}$ & eh2s $3=e h 2 s 1$ \\
\hline 756 & ; & \\
\hline 757 & ; & For HNAPH reaction \\
\hline 758 & $\mathbf{F}$ & $w m=141.7508$ \\
\hline 759 & $\mathbf{F}$ & wtc $=w^{*} w t f e$ \\
\hline 760 & F & $w t o=w n^{*} w t f o$ \\
\hline 761 & $\mathbf{F}$ & wtg $=$ man-wtc-wto \\
\hline 762 & $\mathbf{F}$ & xmolg=wtg/wmix \\
\hline 763 & $\mathbf{F}$ & fcl=wtc/wc. \\
\hline 764 & $\mathbf{F}$ & fol $1=w t o / w o$ \\
\hline 765 & $\mathbf{F}$ & fch41 =xmolg* fch4 \\
\hline 766 & $\mathbf{F}$ & $\mathrm{fc} 2 \mathrm{~h} 61=\mathrm{xmolg} \mathrm{fc} \mathrm{f} 2 \mathrm{~h} 6$ \\
\hline 767 & $\mathbf{F}$ & fc3h81=xmolg $f^{*} c 3 h 8$ \\
\hline 768 & $\mathbf{F}$ & $\mathrm{fco} 21=x \operatorname{mol} g^{\star} \mathrm{fco} 2$ \\
\hline 769 & $\mathbf{F}$ & fh21 =xmolg* fh2 \\
\hline 770 & $\mathbf{F}$ & fhhc1 $=x m o l g *$ fhhc \\
\hline 771 & $\mathbf{F}$ & fh2s 1 =xamolg* fh2s \\
\hline 772 & $\mathbf{F}$ & $f c 2=f c 1$ \\
\hline 773 & $F$ & fo2=fo1 \\
\hline 774 & $\boldsymbol{F}$ & $f \operatorname{ch} 42=f \operatorname{ch} 41$ \\
\hline 775 & $F$ & fc2h $62=f \operatorname{chh} 61$ \\
\hline 776 & $\mathbf{F}$ & fc3h82=fc3h81 \\
\hline 777 & $F$ & $f(c) 22=f c 021$ \\
\hline 778 & $F$ & fh $22=$ fh 21 \\
\hline 779 & $\mathbf{F}$ & fhhc2 $=$ fhhc1 \\
\hline 780 & $\mathbf{F}$ & fh $2 s 2=$ fh $2 s 1$ \\
\hline 781 & $\mathbf{F}$ & $\mathrm{fc} 3=\mathrm{fc} 1$ \\
\hline 782 & $\mathbf{F}$ & fo $3=f o 1$ \\
\hline 783 & $\mathbf{F}$ & $\mathrm{fch} 43=\mathrm{fch} 41$ \\
\hline 784 & $\mathbf{F}$ & fc $2 h 63=f c 2 h 61$ \\
\hline 785 & $\mathbf{F}$ & $\mathrm{fc} 3 \mathrm{~h} 83=\mathrm{fc} 3 \mathrm{~h} 81$ \\
\hline 786 & $\mathbf{F}$ & $f c 023=f c 021$ \\
\hline 787 & $\mathbf{F}$ & fh $23=f h 21$ \\
\hline 788 & $\mathbf{F}$ & fhhc $3=$ fhhc1 \\
\hline 789 & $\mathbf{F}$ & $\operatorname{fh} 2 \mathrm{~s} 3=\mathrm{fh} 2 \mathrm{~s} 1$ \\
\hline 790 & ; & \\
\hline
\end{tabular}




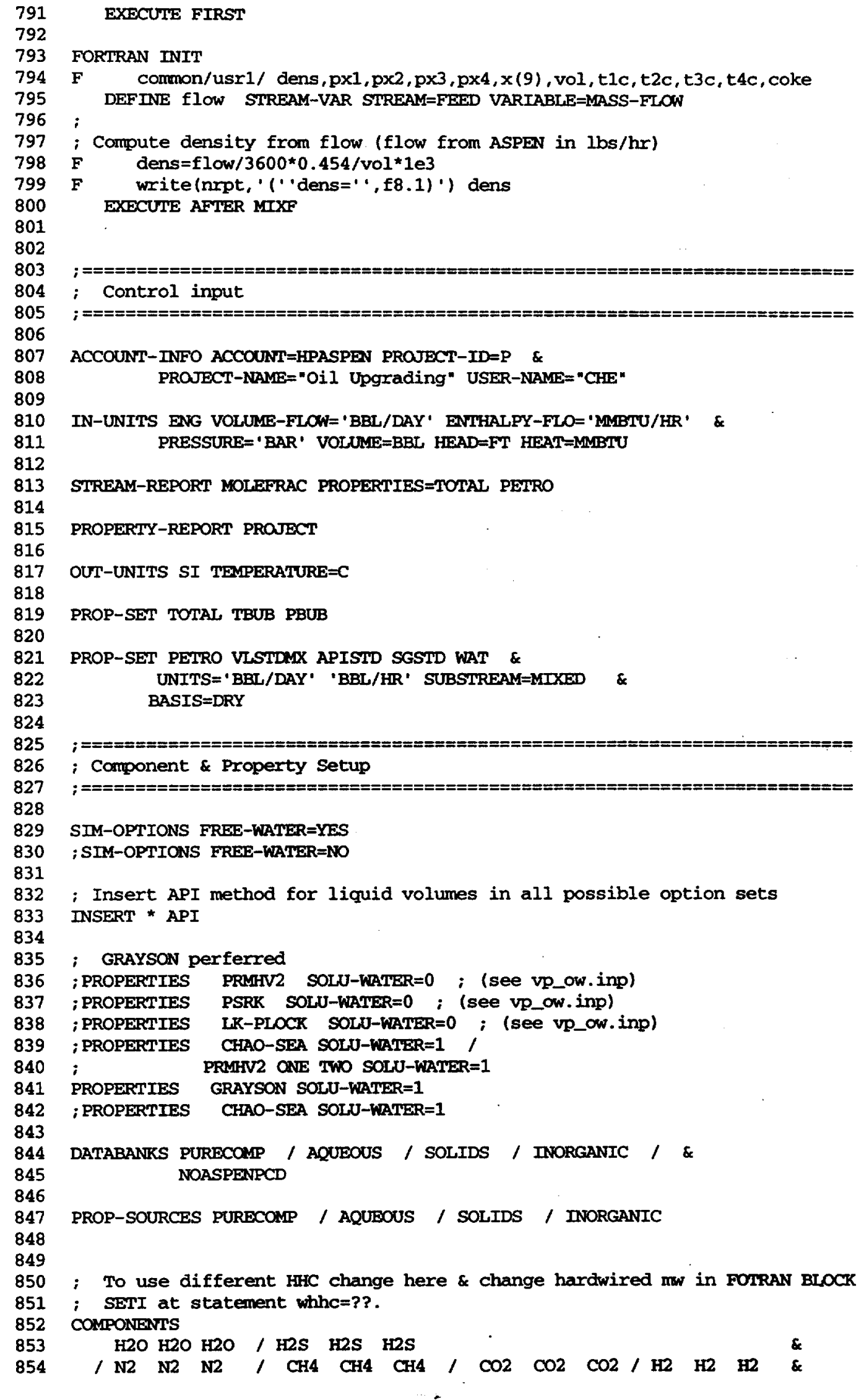




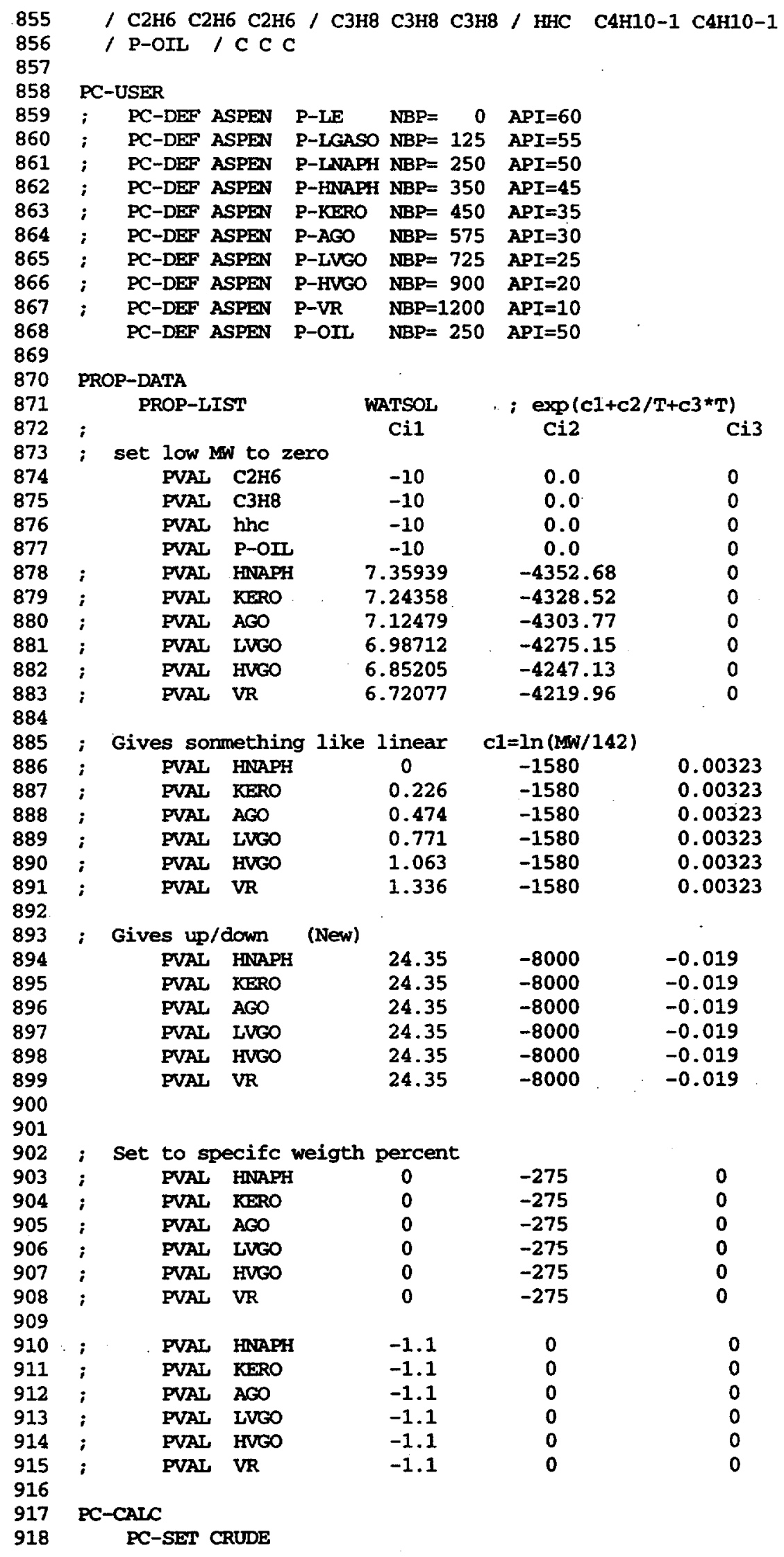




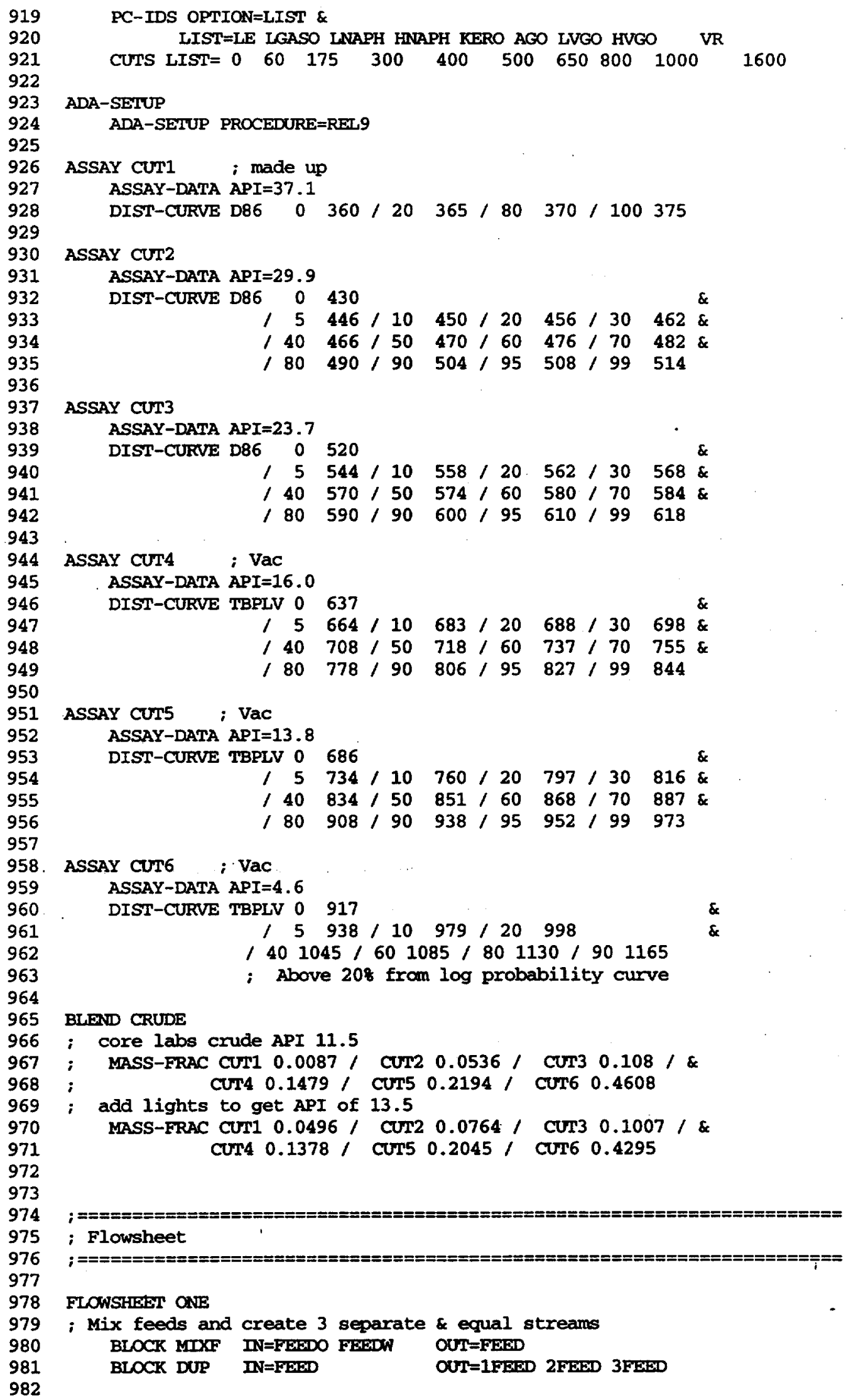

943

944

945

946

947

948

949

950

951

952

953

954

955

956

957

958.

959

960

961

962

963

964

965

966

967

968

969

970

971

972

973

974

975

976

977

978

979

980

981

982

PC-IDS OPTION=LIST \& IIST=LE LGASO LNAPH HNAPH KERO AGO LVGO HVGO VR CUTS LIST $=\begin{array}{lllllllllll}0 & 60 & 175 & 300 & 400 & 500 & 650 & 800 & 1000 & 1600\end{array}$

ADA-SETUP

ADA-SETUP PROCEDURE=REL9

ASSAY CUT1 ; made up ASSAY-DATA API $=37.1$ DIST-CURVE D86 0 360/20 $065 / 80370 / 100375$

ASSAY CUT2 ASSAY-DATA API $=29.9$

DIST-CURVE D86 0430

$/ 5446 / 10450 / 20456 / 30462 \&$

$/ 40466 / 50470 / 60476 / 70482 \&$

$/ 80490 / 90504 / 95508 / 99514$

ASSAY CUT3

ASSAY-DATA API $=23.7$

DIST-CURVE D86 $0 \quad 520$

$/ 5544 / 10558 / 20.562 / 30568 \&$

$/ 40570 / 50574 / 60580 / 70584 \&$

$/ 80590 / 90600 / 95610 / 99618$

ASSAY CUT4 ; VaC

ASSAY-DATA API $=16.0$

DIST-CURVE TBPLV 0637

$/ 5664 / 10683 / 20688 / 30698 \&$

$/ 40708 / 50718 / 60737 / 70755 \&$

$/ 80778 / 90806 / 95827 / 99844$

ASSAY CUTS : VaC

ASSAY-DATA API $=13.8$

DIST-CURVE TBPLV 0686

/ $5734 / 10760 / 20797 / 30816 \&$

$/ 40834 / 50851 / 60868 / 70 \quad 887 \&$

$/ 80908 / 90938 / 95952 / 99973$

ASSAY CUT6 ; Vac

ASSAY-DATA API $=4.6$

DIST-CURVE TBPLV $0 \quad 917$ \&

/5938/10979/20998 \&

/ $401045 / 601085 / 801130 / 901165$

- Above 208 from log probability curve

BLEND CRUDE

; core labs crude API 11.5

MASS-FRAC CUT1 $0.0087 /$ CUT2 $0.0536 / \operatorname{cUT} 30.108 / \&$

CUT4 $0.1479 /$ CUT5 $0.2194 /$ CUT6 0.4608

add lights to get API of 13.5

MASS-FRAC CUT1 $0.0496 /$ CUT2 $0.0764 /$ CUT3 $0.1007 / \&$ Cur4 $0.1378 /$ CUT5 $0.2045 /$ CUT6 0.4295 


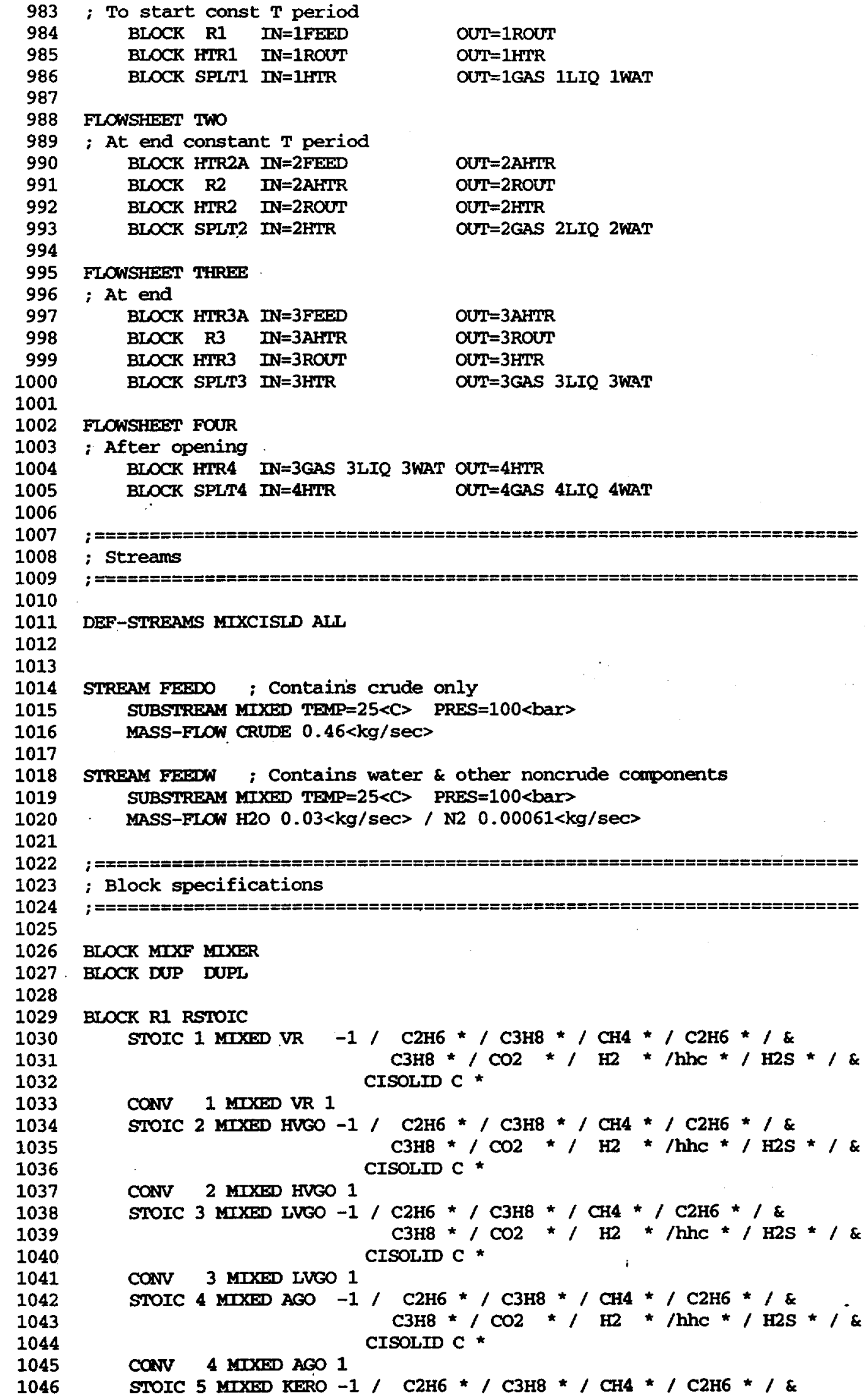

; To start const $\mathbf{T}$ period BLOCK R1 IN=1FEED OUT=1ROUT BLOCK HTR1 IN=1ROUT OUT=1HTR BLOCK SPLT1 IN=1HTR OUT=1GAS 1LIQ 1WAT

FLOWSHEET TWO

; At end constant $T$ period BLOCK HTR2A IN=2FreD BLOCK R2 IN=2AHTR BLOCK HTR2 IN=2ROUT BLOCK SPLT2 IN=2HTR

FLOWSHEST THREE

; At end

BLOCK HTR3A IN=3FEED OUT=3AHTR

BLOCK R3 IN=3AHTR OUT=3ROUT BLOCK HTR3 IN=3ROUT OUT=3HTR BLOCK SPLT3 IN=3HTR OUT=3GAS 3LIQ 3WAT

FLOWSHEET FOUR

- After opening BLOCK HTR4 IN=3GAS 3LIQ 3WAT OUT=4HTR BLOCK SPLT4 IN=4HTR OUT=4GAS 4LIQ 4WAT 
CONV 5 MIXED KERO 1

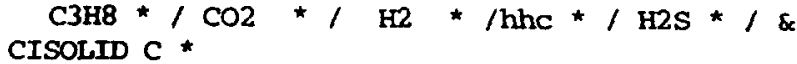

BLOCK R3 RSTOIC

STOIC 1 MIXED VR $-1 / \mathrm{C} 2 \mathrm{H} 6 * / \mathrm{C} 3 \mathrm{H} 8 * / \mathrm{CH} 4 * / \mathrm{C} 2 \mathrm{H} 6 * / \&$ $\mathrm{C} 3 \mathrm{HB} * / \mathrm{CO} 2 * 1 \mathrm{H} 2 * / \mathrm{hhc} * / \mathrm{H} 2 \mathrm{~S} * / \&$ CISOLID $\mathrm{C}$ *

CONV 1 MTXED VR 1

STOIC 2 MIXED HVGO $-1 / \mathrm{C} 2 \mathrm{H} 6$ * / $\mathrm{C} 3 \mathrm{H} 8$ * / $\mathrm{CH} 4$ * / $22 \mathrm{H} 6$ * / \& $\mathrm{C} 3 \mathrm{HB} * / \mathrm{CO} 2 * / \mathrm{H} 2$ * /hhc * / H2S * / \&

CONV 2 MTXED HVGO 1 CISOLID $\mathrm{C}$ *

STOIC 3 MIXED LVGO -1 / C2H6 * / C3H8 * / CH4 * / C2H6* / \& $\mathrm{C} 3 \mathrm{H} 8 * / \mathrm{CO} 2 * / \mathrm{H} 2 * / \mathrm{hhc} * / \mathrm{H} 2 \mathrm{~s} * / *$

CONV 3 MTXED LVGO 1 CISOLID $c$ *

STOIC 4 MIXED AGO -1/ C2H6 */ $\mathrm{CHH} 8 * / \mathrm{CH} 4 * / \mathrm{C} 2 \mathrm{H} 6 * / \&$ $\mathrm{C} 3 \mathrm{HB} * / \mathrm{CO} 2 * / \mathrm{H} 2 * / \mathrm{hhC} * / \mathrm{H} 2 \mathrm{~S} * / \&$ CISOLID $\mathrm{C}$ *

CONV 4 MIXED AGO 1

STOIC 5 MIXED KERO $-1 / \mathrm{C} 2 \mathrm{H} 6$ * / $\mathrm{C} 3 \mathrm{H} 8$ * $/ \mathrm{CH} 4$ * $/ \mathrm{C} 2 \mathrm{H} 6$ * / \& $\mathrm{C} 3 \mathrm{H} 8 * / \mathrm{CO} 2 * / \mathrm{H} 2$ / hhc */ $\mathrm{H} 2 \mathrm{~S} * / \&$ CONV 5 MIXED KERO 1

STOIC 6 MIXED HNAPH $-1 / \mathrm{C} 2 \mathrm{H} 6$ * / $\mathrm{CHH} 8 * / \mathrm{CH} 4 * / \mathrm{C} 2 \mathrm{H} 6 * / \&$

CONV 6 MIXED HNAPH 1 CISOLID $c$ * BLOCK SPLT3 FLASH2 
1136

1137

1138

1139

1140

1141

1142

1143

1144

1145

1146

1147

1148

1149

1150

1151

1152

1153

1154

1155

1156

1157

1158

1159

1160

1161

1162

1163

1164

1165

1166

1167

1168

1169

1170

1171

1172

1173

1174

BLOCK HTRI HEATER DESCRIPTION 'Sets desired flash temperature \& pressuxe' PARAM TEMP $=25<C>$ PRES $=100<$ bar $>$

BLOCK HTR2 HEATER DESCRIPTION 'Sets desired flash temperature \& pressure' PARAM TEMP=25 <C> PRES $=100<$ bar $>$

BIOCK HTR3 HEATER DESCRIPTION 'Sets desired flash temperature \& pressure' PARAM TEMP=25 <C> PRES=100<bar $>$ BLOCK HTR2A HEATER DESCRIPTION 'Sets desired flash temperature \& pressure' PARAM TEMP=25 <C> PRES $=100<$ bar $>$

BLOCK HITR3A HEATER DESCRIPTION 'Sets desired flash temperature \& pressure' PARAM TEMP $=25<C>$ PRES $=100<$ bar $>$

; blow down

BLOCK HTR4 HEATER DESCRIPTION 'Sets desired flash temcerature \& pressure no density it' PARAM TEMP $=25<\mathrm{C}>$ PRES $=100<$ bar $>$

BLOCK SPLT4 FLASH2

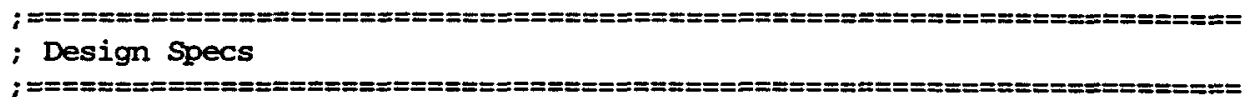




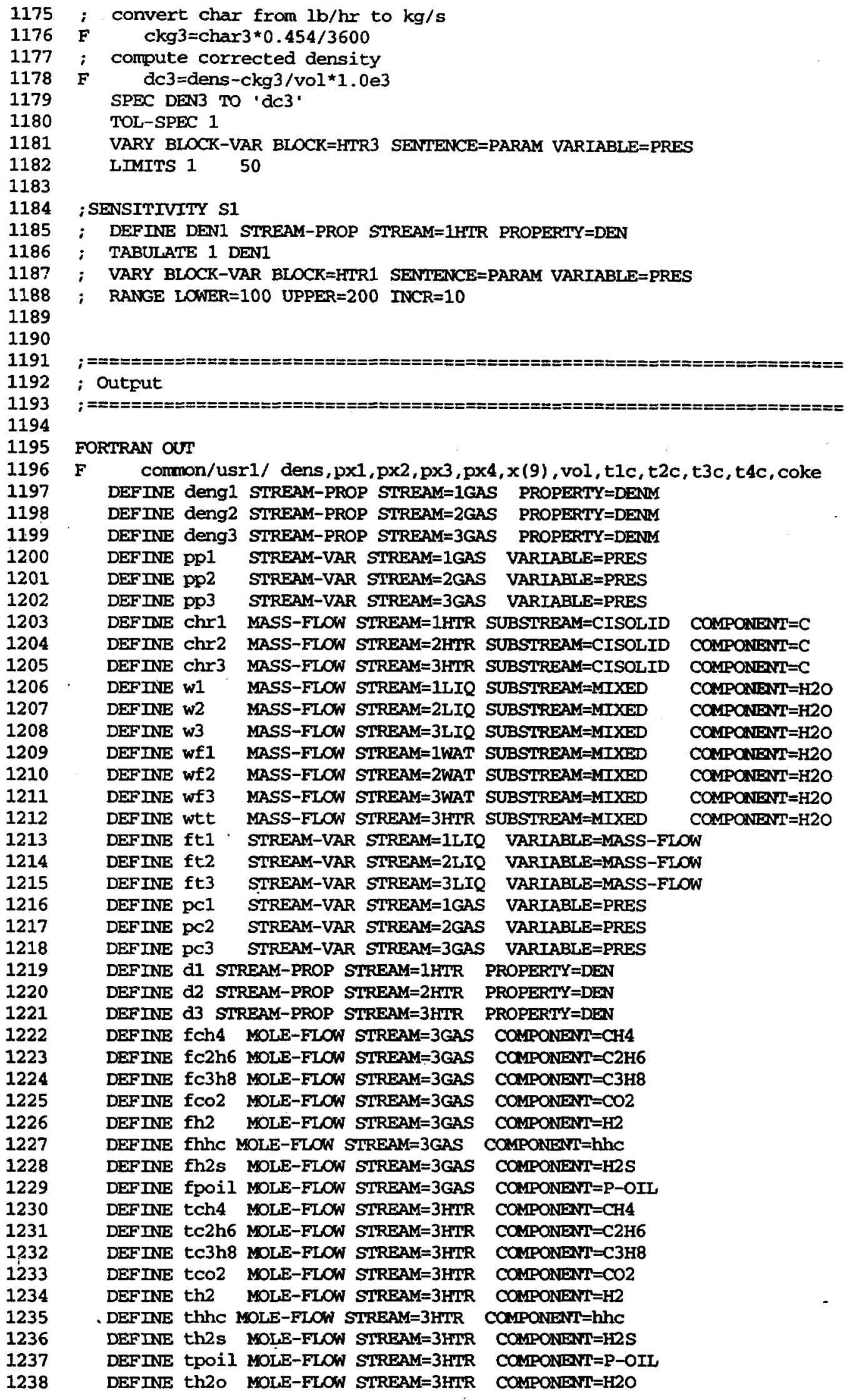


DEF INE api3 STREAM-PROP STREAM=3LIQ PROPERTY=API DEFINE api4 STREAM-PROP STREAM $=4$ LIQ PROPERTY=API sum $=f c h 4+f c 2 h 6+f c 3 h 8+f h 2+f c o 2+f h h c+f h 2 s+f p o i l$ $\mathrm{x} 1=\mathrm{fco} 2 / \mathrm{sum}$ $\mathrm{x} 2=\mathrm{fh} 2 / \mathrm{sum}$ $\mathrm{x} 3=\mathrm{fch} 4 /$ sum $\mathrm{x} 4=\mathrm{fc} 2 \mathrm{~h} 6 / \mathrm{sum}$ $\mathrm{x} 5=\mathrm{fc} 3 \mathrm{~h} 8 / \mathrm{sum}$ $x 6=$ fhhc/sum $x 7=$ fh 2 s/sum $x 8=$ fpoil/sum $x \operatorname{ch} r 1=\operatorname{chr} 1 * 0.454 / 3600$ $\mathrm{xch} \times 2=\mathrm{chr} 2 * 0.454 / 3600$ $x \operatorname{chr} 3=\operatorname{chr} 3 * 0.454 / 3600$ $\mathrm{d} 1 \mathrm{t}=\mathrm{dl}+\mathrm{xchr} 1 / \mathrm{vol} * 1000$ $\mathrm{d} 2 \mathrm{t}=\mathrm{d} 2+\mathrm{xchr} 2 / \mathrm{vol} * 1000$ $\mathrm{d} 3 \mathrm{t}=\mathrm{d} 3+\mathrm{xchr} 3 / \mathrm{vol} 1 * 1000$ $x w 1=w 1 /($ ft $1-\operatorname{char} 1)$ $\mathrm{xw} 2=\mathrm{w} 2 /(\mathrm{ft} 2-\mathrm{char} 2)$ $x w 3=w 3 /($ ft $3-\operatorname{char} 3)$ $z 1=p p 1 * 1.0 e 5 /($ deng $1 * 1000 * 8.314 *(t 1 c+273.15))$ $z 2=p p 2 * 1.0 \mathrm{e} 5 /($ deng $2 * 1000 * 8.314 *(t 2 c+273.15))$ $z 3=\mathrm{pp} 3 * 1.0 \mathrm{e} 5 /($ deng $3 * 1000 * 8.314 *(t 3 c+273.15))$ write (nrpt, '

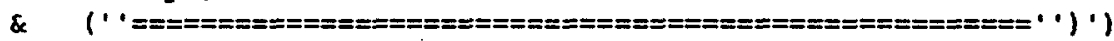
write (nrpt, $' 1$

\& 6x, " Temp Pressure (bar) LIQ/GAS TOTAL') $)$ write (nrpt, ' '

\& $"$ Loc (c) Data Calc Density (kg/cum)," . $\&$ "Density (kg/cum) "l') write (nrpt, 333) ' 1 ',t1c,px1,pc1,d1,d1t write (nrpt, 333) ' $2 \cdot, t 2 c, p \times 2, p c 2, d 2, d 2 t$ write (nrpt, 333) ' 3 ',t3c,px3,pc3,d3,d3t 


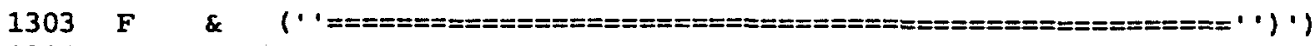
EXECUTE LAST

The following is the listing for the ASCII data file.

1

\$indata

* For Run 126.

$\star$

* Charges all in $\mathrm{kg}^{\prime} \mathrm{s}$ ( $\mathrm{flcr}$ is CRUDE)

flc $x=0.46 \quad f l h 20=0.03 \quad$ fln $2=0.00061$

* Reaction Stoichiometry

* Input basic reaction stoich. wtfc-weight fraction coke

* fch4, fc2h6 rel moles of noncoke prods

* tuned for ASPEN (low water sol at low T)

* wt $f c=0.48$ for $w t f o=0$

wt $\mathrm{f} c=0.192$

wt fo $=0.6$

fch $4=1.0$

fc2h $6=0.390$

$\mathrm{fc} 3 \mathrm{~h} 8=0.269$

fco $2=0.121$

fh2 $=0.025$

fh2s $=0.062$

* butane

fhhc $=0.150$

* Dry N2/O2 + trace free gas composition (For printout only)

* 1-CO2 2-H2 3-CH4 4-C2H6 5-C3H8 6-C4s 7-H2s

$x(1)=0.067$

$x(2)=0.021$

$x(3)=0.684$

$x(4)=0.154$

$x(5)=0.0526$

$x(6)=0.0087$

$x(7)=0.0131$

*

* Coke $(\mathrm{kg})$ for output only

coke $=0.025$

$\star$

* Input extent. er-fraction of input reacted

* ferl-fraction of er in reactor 1 , etc

* er $=0.115$ for wtfo $=0$

er $=0.32$

*

* fer $1=0.42$

fer $1=0.0$

* fer $1=0.011$

fer $2=0.75$

* Input temperatures (C) and pressures(Bar)

* For reactors $1,2 \& 3$

* $t 1 c=426 \mathrm{p} 1=151$

$t 1 c=233 \quad p 1=25.8$

* $t 1 c=363 \mathrm{p} 1=80.5$

t2c=429 p2 $=194$

$t 3 c=25 \quad p 3=23.8$

* Reactor volume (L)

vol $=1.05$

send 


\section{APPENDIX IV.}

\section{ACS MODEL PARAMETERS}

The important parameter used in the ACS modeling of the crude oil systems are described in this appendix. Only those properties not given in the body of the text are included.

Vapor pressures for the five pseudocomponents used for the crude oil and the P-OIL product are calculated using the following simple boiling point relation

$$
\ln \left(P_{v p}\right)=\left(T_{b_{r}} \frac{\ln \left(P_{c}\right)}{1-T_{b_{r}}}\right)\left(1-\frac{1}{T_{r}}\right),
$$

where $P_{v p}$ is the vapor pressure in atmospheres, $T_{b_{r}}$ is the reduced normal boiling point, $T_{r}$ is the reduced temperature, and $P_{c}$ is the critical pressure expressed in atmospheres. The values for the all parameters are given in the report body with the exception of the critical temperature and pressure of the P-OIL which was taken as $587 \mathrm{~K}$ and $3.1 \mathrm{MPa}$ respectively.

In the simulation, six of the components were treated as Henry's Law components. The values of Henry's Law constants as a function of temperature were derived from results obtained from ASPEN PLUS for the crude oil mixture using the GRAYSON property set. The values used are given in Table IV-1. The hydrocarbons where assumed to be normal alkanes.

Table IV-1. Henry's Law constants.

\begin{tabular}{|c|cccccc|}
\hline $\begin{array}{c}\text { Temp } \\
\left({ }^{\circ} \mathrm{C}\right)\end{array}$ & $\begin{array}{c}\mathrm{CO}_{2} \\
(\mathrm{MPa})\end{array}$ & $\begin{array}{c}\mathrm{H}_{2} \mathrm{~S} \\
(\mathrm{MPa})\end{array}$ & $\begin{array}{c}\mathrm{CH}_{4} \\
(\mathrm{MPa})\end{array}$ & $\begin{array}{c}\mathrm{C}_{2} \mathrm{H}_{6} \\
(\mathrm{MPa})\end{array}$ & $\begin{array}{c}\mathrm{C}_{3} \mathrm{H}_{8} \\
(\mathrm{MPa})\end{array}$ & $\begin{array}{c}\mathrm{C}_{4} \mathrm{H}_{10} \\
(\mathrm{MPa})\end{array}$ \\
\hline 10 & 8.6 & 1.3 & 19.1 & 3.6 & 0.98 & 0.19 \\
50 & 16.5 & 2.9 & 24.0 & 5.9 & 2.2 & 0.55 \\
100 & 25.1 & 5.5 & 29.6 & 9.0 & 4.2 & 1.46 \\
200 & 36.4 & 10.8 & 38.2 & 14.1 & 8.6 & 4.2 \\
300 & 41.0 & 16.4 & 41.3 & 16.2 & 12.1 & 7.1 \\
400 & 35.3 & 19.5 & 37.8 & 15.5 & 13.8 & 9.3 \\
450 & 31.3 & 19.8 & 34.0 & 14.1 & 13.7 & 10.1 \\
\hline
\end{tabular}

The model also requires pure component densities to be defined. The most important of these are for the oil pseudocomponents and water. The water densities used were taken from saturated steam tables and are listed in Table IV-2. 
Table IV-2. Liquid water density.

\begin{tabular}{|cc|}
\hline $\begin{array}{c}\text { Temp } \\
(\mathrm{K})\end{array}$ & $\begin{array}{c}\text { Density } \\
\left(\mathrm{kg} / \mathrm{m}^{3}\right)\end{array}$ \\
\hline 283 & 1001 \\
311 & 995 \\
366 & 965 \\
422 & 919 \\
477. & 861 \\
533 & 786 \\
589 & 680 \\
616 & 599 \\
630 & 540 \\
644 & 435 \\
\hline
\end{tabular}

Oil pseudocomponent densities were assumed to be linearly dependent on temperature. Their values were specified by the two points given for each component in Table IV-3.

Table IV-3. Oil component densities at two temperatures.

\begin{tabular}{|c||c|c|}
\hline \multicolumn{1}{|c||}{} & \multicolumn{2}{c|}{ Density $\left(\mathrm{kg} / \mathrm{m}^{3}\right)$} \\
\cline { 2 - 3 } HNAPH & At 294 K & At 627 K \\
\cline { 2 - 3 } KERO & 847 & 400 \\
AGO & 879 & 658 \\
LVGO & 913 & 696 \\
HVGO & 956 & 750 \\
VR & 972 & 770 \\
\hline
\end{tabular}

